\title{
FRÜHE ENTWICKLUNGSSTADIEN DES KOPF- UND RUMPF- SKELETTS VON ACANTHIAS VULGARIS
}

\author{
VON \\ J. W. VAN WIJHE \\ IN GRONINGEN. \\ Mit Tafel XI und 4 Textfiguren.
}

Der Hauptzweck dieser Arbeit ist eine Nachuntersuchung der Entwicklung des Kopfskeletts von Acanthias vulgaris, deren Kenntnis wir der grundlegenden Abhandlung von Sewertzoff (1899) verdanken. Es mussten dabei aber auch die Entwicklung des Rumpfskeletts und die Metamerie des Kopfes berücksichtigt werden. Fragen die nur den hinteren Abschnitt der Wirbelsäule betreffen, wie diejenige über Wirbelverdoppelung, fallen nicht in den Kreis dieser Arbeit.

Auf dem 6. internationalen Zoologencongress (Bern, 1904) machte ich eine Mitteilung über Schädelentwicklung bei Selachiern und demonstrierte dieselbe an Methylenblaupräparaten ganzer oder halbierter Embryonen. Mit ausführlicherer Publizierung sollte gewartet werden, bis ich eine genügende Zahl vom Längs- und Querschnittserien besitzen würde. Die Arbeit wurde lange Zeit unterbrochen und erst nach dem Kriege, als die Quelle aus Helgoland nicht länger verschlossen war, wieder aufgenommen.

Während des Krieges erhielt ich durch die freundliche Vermittlung von Prof. J. S. KINGSLEY viele junge Stadien, bis zum Anfang der Knorpelbildung, aus Boston, Mass. Sie wurden mit Karmin gefärbt zum Teil in Schnittserien zerlegt, zum Teil zu Totalpräparaten verwendet. So kam ich allmählich in den Besitz einer Serie Totalpräparate von Embryonen mit 1 bis 83 Segmenten in welcher fast jede Segmentzahl vertreten ist.

Mein verstorbener Freund, Dr. P. P. C. HoEk, weiland Direktor der zoologischen Station in Helder, verschaffte mir viel Material an welchem die Skelettentwicklung studiert werden konnte und das mit Methylenblau gefärbt zu Totalpräparaten verwendet wurde.

Meine reichlichste Quelle aber war die Biologische Anstalt auf Helgoland, deren Direktion ich zu besonderem Danke verpflichtet bin.

Fixierung der lebenden Embryonen in Sublimat-Formol ist meines Wissens die beste Methode zur nachherigen Färbung des Knorpels mit Methylenblau oder auch - wir ich später fand - mit Victoriablau. Bei jüngeren Embryonen erhält man nach dem Ausziehen mit salzsaurem Alkohol nur den Knorpel gefärbt. Bei älteren Embryonen bleibt auch der Schleim in den Schleimkanälen (Seitenund Ampullarorganen) blau. Nach mehr als 20 Jahren sind die Präparate nicht merklich verblasst.

In meiner ersten Mitteilung über Methylenblaufärbung des Knorpels (1902) wurde gesagt, dass dieselbe auch an nach ZENKER fixierten Präparaten gelinge. Bald aber erfuhr ich, dass sie dann ganz unzuverlässig ist. Bei kurzer Einwirkung der ZENkERschen Mischung bleibt nach dem Färben und Ausziehen nur das Innere der Knorpelstücke - wo die Mischung kaum eingewirkt hat — blau, die Peripherie nicht. Bei längerer Einwirking der Mischung bleibt die Blaufärbung ganz aus. Ein ähnlich unzuverlässiges Resultat erhält man, wenn man zur Bereitung der Fixierungsflüssigkeit Essigsäure-Sublimatlösung statt reiner Sublimatlösung mit Formol mischt. Im Gegensatz mit Salzsäure wirkt Essigsäure vernichtend auf das Vermögen des Knorpels den Farbstoff festzuhalten.

Nach Fixierung in reiner Sublimatlösung bleibt die Knorpelgrundsubstanz bekanntlich farblos in 
Ammoniumkarminlösung. Hat man aber Essigsäure-Sublimatlösung längere Zeit einwirken lassen, so ist ein völliger Umschlag im Verhalten der Knorpelgrundsubstanz zum Karmin und Victoriablau eingetreten. Dieselbe gibt nicht nur das Blau sofort in Alkohol ab, sondern färbt sich auch im Karmin tiefrot.

Die Längsschnittserien aus früheren Jahren wurden von Material, das nach ZENKER fixiert war, angefertigt (das mit Sublimat-Formol fixierte wurde $\mathrm{zu}$ Totalpräparaten verwendet). Die grossenteils mit Alaunhaematoxylin gefärbten, zum Teil mit Eosin nachbehandelten Schnitte lassen den Knorpel kaum hervortreten.

Von dem die letzten Jahre aus Helgoland erhaltenen Materiale wurden Querschnittserien angefertigt. Die Embryonen wurden einige Wochen lang in alkoholischer Ammoniumkarminlösung (ein promille Ammoniumkarmin in 60 bis 70 prozentigen Alkohol) gefärbt und dann in Schnitte von $15 \mu$ Dicke zerlegt. Die Färbflüssigkeit wird hergestellt, indem man eine frisch bereitete 1 prozentige wässerige Lösung des Karminpulvers in das 9 fache Volumen Alkohols ausgiesst. Zur Blaufärbung der Knorpelgrundsubstanz verweilten die Objektträger mit den aufgeklebten Schnitten etwa 6 Stunden in 1 promille Victoriablau (wir hätten auch Methylenblau nehmen können) gelöst in 60 bis 70 prozentigen Alkohol.

Wurden ungefärbte oder unvollkommen durchfärbte Embryonen genommen, so genügte ein zweistündiger Aufenthalt der aufgeklebten Schnitte in der Karminlösung zur Kernfärbung. Ein schöneres Resultat erhält man nach einem Aufenthalt von etwa 24 Stunden. Das Ausziehen mit salzsaurem Alkohol wurde unterlassen, da die Gewebefärbung, rosa bis rot in verschiedenen Tönen, ein Vorteil ist. Namentlich die Nerven treten dabei gut hervor. Will man die roten Blutkörperchen gelb hervortreten lassen, so löse man eine Spur Ammoniumpikrat in den absoluten Alkohol (oder den Karbolxylol) vor dem Übertragen der Schnitte in Xylol.

Nach den Querschnittserien von Embryonen, resp. von 23; 28 und $39 \frac{1}{2} \mathrm{~mm}$ Länge hat der Amanuensis, Herr P. J. DE VRIES, mittelst der Plattenmodelliermethode drei Modelle des Chondrokraniums hergestellt. Diese Stadien sollen ausführlicher behandelt werden.

Die Knorpelentwicklung kann bei Embryonen, die in verschiedenen Lokalitäten dem Muttertiere entnommen wurden, beträchtlich variieren. So fand ich den ersten Knorpel (das Parachordale) in Exemplaren aus Helgoland und Helder schon bei solchen von $22 \mathrm{~mm}$ Länge; in Exemplaren aus Boston ') aber erst bei einer Länge von $32 \mathrm{~mm}$ (gekrümmte Exemplare wurden mittelst eines Fadens gemessen). Vielleicht hat auch die Jahreszeit Einfluss. Die Helgoländer Embryonen erhielt ich im Sommer. In späteren Stadien ist ihr Knorpelskeletî viel weiter entwickelt als bei den Embryonen aus Helder von gleicher Körperlänge, die im Winter gesammelt wurden.

Wenn das Parachordale gerade knorpelig geworden ist, sieht man dasselbe an mit Methylenblau behandelten Totalpräparaten als eine paarige blaue Platte, die in der Region der Gehörblase liegt und sich noch mit etwa $1 / 3$ ihrer Länge weiter kaudalwärts erstrekt. Vorn und hinten endet die Platte zugespitzt am dorsalen Rande der Chorda. Man kann sich an diesen Präparaten nicht überzeugen, ob der Knorpel schon das hintere Ende des künftigen Schädels erreicht hat oder nicht, denn von einem knorpeligen Occipitalbogen, der den hinteren Schädelteil kennzeichnet, ist noch nichts-zu sehen.

\section{Querschnittserie durch einen Embryo von $23 \mathrm{~mm}$ Länge.}

Modell Fig. $1 a$ und $1 b$, Taf. XI.

Auch bei diesem Embryo ist das Parachordale noch der einzige Knorpel im ganzen Körper (Exemplare von $20 \mathrm{~mm}$ Länge zeigen noch keine Knorpelbildung).

Die Querschnittserie zeigt jederseits die sehr geräumige Prämandibularhöhle des. 1. Somites. Die Höhlen des 2. und 3. Somites sind verschwunden. Ihre Wände haben die Anlagen des M. obl. sup. und rectus lateralis geliefert. Der N. trochlearis und der N. abducens sind vom Gehirn bis in ihre Muskelanlage zu verfolgen. Kurz bevor der N. trochlearis seinen Muskel erreicht, durchbricht er eine kleine Platte verdichteten Mesenchyms, das bei älteren Embryonen zur Cartilago supraorbitalis verknorpelt.

1) Es ist aber nicht ausgeschlössen, dass bei der Fixierung dieser Embryonen Essigsäure-Sublimatlösung verwendet wurde, welche, wie erwähnt, die selektive Knorpelfärbung hemmt. Dann aber zeigt, nach Färbung mit Victoriablau, nicht der Knorpel, sondern das Stroma der roten Blutkörperchen nach dern Ausziehen einen hellblauen Ton. 
An der Wand der Prämandibularhöhle sieht man die Anlagen der vom N. oculomotorius versorgten Augenmuskeln. Die Kommissur welche in früheren Stadien die beiderseitigen Prämandibularhöhlen verband, ist als ein solider' Strang, der die Wände der beiderseitigen Höhlen mit einander verbindet, deutlich erkennbar und liegt in der Basis des Pulvinus cerebri (Mittelhirnpolster, GaupP).

In dieser Basis liegt auch das ventral- und rückwärts ${ }^{1}$ ) hakenförmig umgebogene Chordaende. Die Chordaspitze am Ende des Hakens berührt noch die solide Kommissur des beiderseitigen 1. Somites, wie dies bekanntlich in früheren Stadien der Fall ist bevor die Chorda hier, wohl zufolge der starken Mittelhirnbeuge, die charakteristische Hakenform angenommen hat.

Das verdichtete Mesenchym der Kommissur setzt sich auch in den Chordahaken fort, dessen Krümmung ausfüllend und bildet von hier aus lateralwärts einen Flügel, der über den Augapfel hinzieht. In diesem Flügel, der sich ohne scharfe Grenze in das umgebende lockere Mesenchym verliert, entsteht nachher die Cartilago antotica, welche mit der Cart. supraorbitalis verschmelzend, den Pleurosphenoidknorpel bildet. Sewertzoff, der Entdecker desselben, nennt ihn Alisphenoid; ich ziehe die erwähnte, mehr indifferente Bezeichnung vor.

Wegen der später verschiedenen Schicksale muss man das in der Basis des Hirnpolsters liegende unpaare Mittelstück von dem paarigen Flügel unterscheiden. Das Mittelstück wird uns später interessieren. Der Ursprung desselben füllt nicht nur die Krümmung des Chordahakens aus, sondern umgibt auch allseitig die dem Infundibulum zugekehrte Hakenspange (welche mit der Chordaspitze endet) und setzt sich kaudalwärts vom Haken noch eine kurze Strecke längs dẹr ventralen Fläche der Chorda fort, erreicht aber das vordere Ende des Parachordale noch nicht.

Rostralwärts endet das Mittelstück am Infundibulum und bildet demselben gleichsam eine Stütze.

Am Gipfel des Hirnpolsters sieht man den N. oculomotorius aus dem Mittelhirn hervortreten. Er kreuzt den Unterrand des erwähnten Flügels um zu seinen Muskelanlagen zu gelangen.

Im Parachordale fängt die blaue Verknorpelung am vorderen Rande der Ohrkapselregion an. Der N. abducens schwingt sich über der vorderen Knorpelspitze in den künftigen Schädelraum und verlässt etwas weiter kaudalwärts mit drei hinter einander liegenden Wurzelbündeln das Gehirn.

Der kräftigste Teil des Parachordale ist derjenige, welcher sich in der hinteren Hälfte der otischen Region befindet. Hier nimmt das Parachordale an jeder Seite der Chorda die ganze Höhe derselben ein, eine Stelle also, welche am Rumpfe den später entstehenden dorsalen und ventralen Bogenanlagen entspricht. Hier hat es auch angefangen lateralwärts einen dünnen flügelartigen Knorpelforsatz, die Lamina basiotica, unter die sonst noch knorpelfreie Ohrkapsel zu schieben. Embryonen von Amia zeigen nach PEHRSON (1922, Fig. 2 und 4) die interessante Abweichung, dass nicht der eigentliche Körper des Parachordale, welcher der Chorda anliegt, sondern der laterale Flügel, die Lamina basiotica, zuerst auftritt (schon mit Polknorpel und Trabecula verschmolzen). Erst später (1.c. Fig. 6) setzt sich die Lamina - von PeHrson nicht mit einem besonderen Namen bezeichnet - in den sich bildenden Körper des Parachordalknorpels fort.

Diese frühe Beziehung zur Ohrkapsel verstärkt die Auffassung nach welcher die Befestigung des Gleichgewichtsorganes den ersten Anstoss zur Schädelbildung gegeben hat.

Hinter der Ohrkapsel tritt der N. hypoglossus über dem Parachordale aus der Medulla oblongata. An der rechten Körperseite tritt er aus mit drei Wurzeln $x, y, z$; an der linken Körperseite besitzt er nur zwei Wurzeln $y, z$; die vorderste Wurzel $x$, welche an der linken Körperseite fehlt, ist an der rechten Seite rudimentär. Sie verlässt das Hirn als ein einziges Bündel, das nur auf einem Schnitt sichtbar ist. Die zweite Wurzel $y$ entspringt an der rechten Körperseite mit zwei, an der linken mit drei getrennten Bündeln. Die dritte Wurzel $z$ weist rechts und links zwei Ursprungsbündel auf.

Die Wurzeln sind bis in ihre Myotome zu verfolgen. Man sieht an jeder Körperseite aber vier Myotome: $W, X, Y, Z$. 'Das vorderste rechte und die beiden vordersten linken haben ihre Nervenwurzeln verloren. Das Myotom $Z$ ist einheitlich. Die Myotome $W, X, Y$ aber sind, wie HoffmanN (1897) gefunden hat, durch eine Mesenchymplatte, welche vorn von der Vaguswurzel ${ }^{2}$ ) durchzogen

1) Dieser Ausdruck ist nur topographisch gemeint, so wie man sagen könnte das Vorderhirn sei ventral- und rückwärts unter das Hinterhirn gebogen. Morphologisch ist die Spitze der Chorda, gebogen oder gerade, ihr vorderes Ende. 2) Die Teilung einiger Occipitalmyotome durch die Wurzelplatte des Vagus kommt nach KolTzoff (1902) auch 
wird, in zwei Stücke geschnitten. Der dorsale Teil liegt lateral, der ventrale medial von der Vagusplatte. Von den Myotomen $X$ und $Y$ sind beide Stücke gut entwickelt, im Gipfel des dorsalen Stückes ist noch ein Rest der Myocöls vorhanden. Myotom $W$ ist aber in solchem Grade degeneriert, dass sein ventrales Stück auf der Querschnittserie nicht mehr mit Sicherheit zu erkennen ist. Sein dorsales Stück ist zwar klein, aber noch deutlich vorhanden; dasselbe umschliesst noch eine Höhle, deren Wände aber angefangen sind sich in Mesenchym aufzulösen.

Das Parachordale erreicht in der Region der dritten Hypoglossuswurzel, obgleich auf dem Querschnitt sehr verschmächtigt, noch den ventralen Chordarand, zieht sich weiter kaudalwärts aber bald von diesem Rande zurück. Dann erhält es sich noch am dorsalen Chordarand als ein sehr dünner Knorpelstreifen bis kurz hinter dem Austritt des ersten Spinalnerven, d. h. des ersten Nerven mit ventraler und dorsaler Wurzel und grossem Ganglion.

Weiter kaudalwärts hört jede Knorpelbildung auf. Im Rumpfe zeigen die Anlagen der Bogen und Intercalaria noch keine Verknorpelung.

Die Accessoriuswurzel des Vagus erstreckt sich durch das frühere dorsale Wurzelgebiet des Hypoglossus und endet im Ganglion des ersten Spinalnerven. Sie ist aus der Nervenleiste entstanden, die im vorderen Rumpfteile schon verschwunden ist und bildet jetzt auf jeder Körperseite zwei längliche gangliöse Anschwellungen. Die eine fängt in der Region der vorletzten, die zweite in der Region der letzten Hypoglossuswurzel an. Dieselben sind Reste der Hypoglossusganglien früherer Stadien.

Die Accessoriuswurzel ist derjenigen der Embryonen höherer Tiere, speziell auch des einmonatlichen Menschenembryos so ähnlich, dass ich ihre Homologie nicht bezweifeln kann, obgleich sie sich bei Acanthias (und den Selachiern überhaupt) später rostralwärts zurückzieht, beim Menschen dagegen eine Strecke spinalwärts wächst. In ihrem jetzigen Stadium ist sie mehr zellig als faserig; später gewinnen die Fasern die Überhand. Dieselben müssen aus der Medulla stammen und den zelligen Strang als Bahn benutzen um zum Vagus zu gelangen.

Wiewohl die beiden vordersten Spinalganglien sich in späteren Entwicklungsstadien mehr oder weniger zurückbilden, stehen sie doch bis in das Stadium von circa $30 \mathrm{~mm}$ Länge noch auf der Höhe ihrer Entwicklung. Dann ist aber bei Embryonen aus Helgoland auch die hintere Grenze des Schädels am knorpeligen Occipitalbogen kenntlich.

In unserem Stadium von $23 \mathrm{~mm}$ Länge ist zwar noch kein knorpeliger Occipitalbogen vorhanden, doch ist die hintere Grenze des Schädels schon gebildet. Auf der Querschnittserie zeigt sich nämlich zwischen der letzten Hypoglossuswurzel und der Ventralwurzel des ersten Spinalnerven ein hoher Bogen, der aus verdichtetem Mesenchym besteht, das wegen der bald folgenden Chondrifizierung als Vorknorpel bezeichnet werden muss.

Der auf dem hinteren Ende des Parachordale stehende Bogen ist an jeder Körperseite auf zwei Schnitten sichtbar und wird noch nicht von der vor seiner Basis hervortretenden Hypoglossuswurzel $z$ durchbohrt, wie das bald nach der Verknorpelung der Fall ist.

Rostralwärts sieht man keine solche bogenartigen Erhebungen auf dem Parachordale.

SEwertzoff (1899) behauptet mit Recht gegen Hoffmann, dass das Parachordale auch in der Occipitalregion als ein einheitliches Ganze verknorpelt. Er glaubt aber an demselben in dieser Region noch segmentale Erhebungen wahrzunehmen, die er auf seinen Rekonstruktionen Fig. 4 und 5 auch abbildet. Ich finde dieselben weder auf meinen Schnittserien, noch auf den Totalpräparaten und halte die beiden Rekonstruktionen für irreführend, die zweite um so mehr, da das Visceralskelett auf derselben in der Form von blauen kontinuierlichen Spangen wiedergegeben ist. Die übrigen Abbildungen von Acanthias stimmen mit meinen Präparaten ganz gut überein.

bei Embryonen von Petromyzon vor und darf nicht verwechselt werden mit der bei Gnathostomen später auftretenden Teilung der hinteren Kopf- und sämtlichen Rumpfmyotome durch die Lateralisplatte des Vagus in der Höhe der Chorda. Diese letztere Teilung, welche die Seitenmuskulatur bekanntlich in einen dorsalen und ventralen Abschnitt trennt, fehit bei Petromyzon, kommt aber bei den Grathostomen mit Ausnahme von Lepidosteus allgemein vor.

Die Wurzelplatte des Vagus erstreckt sich nur in den dorsalen Abschnitt der erwähnten Occipitalmyotome. 


\section{Kopfmyotome in jüngeren Stadien.}

Es ist hier vielleicht am Platz die metotischen Somite (Occipitalsomite) in jüngeren Stadien auf Sagittalschnittserien zurückzuverfolgen um damit ihre Totalzahl zu bestimmen. Ich muss mich dabei kurz fassen und kann keine Abbildungen geben. Der Leser sei verwiesen auf die instruktiven Textfiguren (speziell Fig. 11 bis 16 nach Embryonen von 9 bis 20,6 mm Länge) der inhaltreichen Arbeit von Scammon (1911). Bei mehr entwickelten Embryonen hat Scammon das Auftreten des Knorpels, wohl infolge seiner Fixierungsmethoden, zu spät erkannt.

Sobald man den Occipitalbogen erkennen kann (bei Embryonen von $23 \mathrm{~mm}$ Länge) ist, wie erwähnt, das morphologische Hinterende des Schädels gegeben und haben wir einen fixen Punkt um von hier aus rostralwärts die Myotome zu zählen.

Hinter diesem Bogen folgt der erste Spinalnerv mit ventraler und dorsaler Wurzel und grossem Ganglion. Das Ganglion ermöglicht uns das hinterste Kopfmyotom, z.B. noch bei Embryonen von $15 \mathrm{~mm}$ Länge, zu bestimmen.

Bei jüngeren Embryonen versagt dies Merkmal allmählich. Dann kann man aber die vorderen Occipitalmyotome durch ihre Lagerungsbeziehungen zum Vagus und Glossopharyngeus identifizieren.

Auf diesem Rückwege werden vier Etappen (Sagittalschnittserien durch Embryonen resp. von $19,15,10$ und $7 \frac{1}{2} \mathrm{~mm}$ Länge) genügen.

Embryo von $19 \mathrm{~mm}$ Länge. Nicht mehr als vier Occipitalmyotome: $W, X, Y, Z$ sind vorhanden. Von denselben sind $X, Y, Z$ noch nicht durch die Mesenchymplatte der Vaguswurzel geteilt. $Z$ wird übrigens, so viel mir bekannt ist, auch später nicht von dieser Platte angegriffen. $W$ ist aber schon durch den Vagus in ein ventrales und dorsales Stück geschnitten. Das medial vom Vagus liegende ventrale Stück wird fast ganz von demselben bedeckt; es ist niedrig und strebt nur mit seiner hinteren Spitze ein wenig über den Hinterrand des Vagus empor. Die wenigen Muskelfasern sind deutlich. HOFFMANN (1897) fand aber, dass sie schon bei Embryonen von $20 \mathrm{~mm}$ Länge anfangen zu verschwinden und konnte sie bei solchen von $22 \mathrm{~mm}$ Länge nicht mehr auffinden. Dies stimmt mit unseren Befunden beim Embryo von $23 \mathrm{~mm}$ Länge überein.

Embryo von $15 \mathrm{~mm}$ Länge mit 79 Myotomen hinter dem Vagus. Nicht mehr als vier Occipitalmyotome: $W, X, Y, Z$ sind vorhanden, sämtlich noch ungeteilt. Der Hinterrand des Vagus berührt aber den Vorderrand des hinter ihm hinaufgewachsenen Myotomes $W$. Die Teilung war hier im Begriffe anzufangen.

Der Vagus deckt eine Zellmasse ohne Muskelfasern, die sich dem Vorderrande der ventralen Partie des Myotoms $W$ anschliesst und dem schon abortierten Myotom $V$ entspricht.

Embryo von $10 \mathrm{~mm}$ Länge mit 66 Myotomen hinter dem Vagus. Das vom Vagus ganz gedeckte niedrige Myotom $V$ weist noch einige Muskelfasern auf, die im Begrifle stehen zu verschwinden. Das Myotom erhält die Nummer 6 in der Reihe der Kopfsegmente wenn man von vorn her zählt.

Embryo von $7 \frac{1}{2} \mathrm{~mm}$ Länge mit 56 Myotomen hinter dem Vagus. Das vom Vagus ganz gedeckte Myotom $V$ besitzt in seiner hinteren Hälfte deutliche Muskelfasern. In seiner vorderen Hälfte (die bis zum Vorderrand des Vagus rostralwärts reicht) kommen dieselben auch in jüngeren Stadien nie recht zur Entfaltung. Seinem Vorderrande schliesst sich eine undeutlich begrenzte Zellmasse an, die nach aussen vom Glossopharyngeus gekreuzt wird und ein Rest des Somites $U$ bildet. Dies Somit, das 5 . in der Reihe von vorn her gezählt, ist das erste metotische oder Occipitalsomit und bringt es nie zur Bildung von Muskelfasern, wie ich mit HofFmanN (1897) gegen BRAUS (1899) finde. Auch GoOdRICH (1918) fand in diesem Somit niemals Muskelfasern. Wahrscheinlich hat sich BRAus hier in der Identifizierung des Somites geirrt.

Das Resultat dieser Untersuchung ist, dass bei Acanthias sechs Occipitalsomite : $U, V, W, X, Y, Z$ vorkommen, wie HoFfmanN gefunden hat. BRAUS hat scheinbar ein Somit mehr beobachtet, weil er den ersten Spinalnerv, dessen ventrale Wurzel bei Spinax niger - nicht bei Acanthias - secundär in den Schädel aufgenommen wird (sieh Kap. 5) für den letzten Occipitalnerv gehalten hat. Seine Myotome $T, U, V, W, X, Y, Z$ sind mit den oben erwähnten so zu identifizieren, dass sein Myotom $T$ meinem $U$ etc.; sein Myotom $Y$ meinem $Z$ entspricht. Auf die Frage, ob diese Identifizierung für jeden besonderen Fall zutreffe, kann ich hier nicht eingehen. 
Von einem Vorwärtsrücken der Myotome unter dem Vagus habe ich wie auch DoHRN (1901) und GoodRICH (1918) nichts wahrgenommen.

Dass ich früher glaubte, es existierten statt sechs nur fünf Occipitalsomite kam durch die Spärlichkeit an älteren Stadien in meinem damaligen Material (Scyllium und Pristiurus). Dadurch ist mir das Schicksal des Myotomes $W$ entgangen und fand ich immer nur drei Occipitalmyotome $X, Y, Z$ hinter dem Vagus hinaufgewachsen. Später habe ich- auch bei Scyllium das vor dem dorsalen Gipfel des $X$ abortierende dorsale Stück des Myotoms $W$ angetroffen ${ }^{1}$ ).

Dem Selachierschädel, der dorsal ${ }^{2}$ ) mit dem Occipitalbogen endet, entsprechen also drei prootische Somite, ein hypotisches Somit (das 4. der Reihe) und sechs metotische, im Ganzen 10 Somite. Somit $W$ ist das 7., $X ; Y, Z$, die ich früher für das 7. 8. und 9. gehalten habe, sind das 8. 9. und 10. in der Reihe der Kopfsomite.

Hierin weiche ich von GOODRICH ab, der in seiner wertvollen Arbeit mit sehr instruktiven Abbildungen zum Resultate kommt — obgleich nicht ohne Zweifel - dass es bei Scyllium nur 7 Kopfsomite gäbe, nämlich drei prootische und nur vier metotische Somite. Ein hypotisches Somit (das 4. nach meiner Nomenklatur) existiere nicht.

Wenn ich nun seine Abbildungen 1.c. Fig. 11 (Embryo des Stadiums J) und Fig. 9 (Embryo von $26 \mathrm{~mm}$ Länge) mit einander vergleiche, so gehört nach meiner Erfahrung das erste gut ausgebildete Ganglion (das sich beim Auftreten des knorpeligen Occipitalbogens allmählich zurückbildet) zum ersten Spinalnerven ${ }^{3}$ ). Diesem Ganglion entspricht das mit 10 bezeichnete Myotom auf Fig. 11, aber das mit 9 angedeutete auf Fig. 9 (von der Accessoriuswurzel des Vagus hängt noch ein rudimentäres Ganglion hinab). GOODRICH ist nämlich dasselbe passiert wie mir früher:' er hat nicht bemerkt, dass in der Zwischenzeit sein Myotom 6 der Fig. 11 (das ich oben, nach der Fürbringerschen Nomenklatur, mit $W$ bezeichnet habe) verschwunden ist. Auf Fig. 9 sollten die Myotome deshalb statt mit 6 bis 9 nach seiner eigenen Nomenklatur mit 7 bis 10 (nach meiner jetzigen Nomenklatur mit 8 bis 11) numeriert sein.

Was nun die von GoodRIcH verneinte Frage betrifft, ob ein hypotisches Somit (das 4. der Reihe) um die Zeit des Auftretens der 3. Kiementasche existiere oder nicht, so bemerke ich, dass er nur über Scyllium canicula gearbeitet hat. Bei dieser Spezies konnte ich seiner Zeit, trotz vieler Mühe, die Grenzen des 4. Somites nicht gehörig auffinden, gelangte aber bei Embryonen der viel grösseren Eier von Scyllium catulus (Scyllium stellare, Catulus stellaris) zum Ziel. Hier sind die Schnittbilder über die Segmentierung des Kopfmesoderms viel deutlicher als bei Scyllium canicula. Der Leser vergleiche die Abbildungen von GoodRICH (1918, Fig. 1, 2, 3) mit den meinigen (1882 oder 1915, Fig. 1 und 2).

Catulus ist als besonderes Genus von Scyllium getrennt worden und ich kann aus entwick-

1) So finde ich z.B. folgendes in der Sagittalschnittserie durch einen Embryo von Scyllium catulus des Stadiums $\mathrm{O}$, aus welcher ich früher (1882, Fig. 20-22) drei Abbildungen gegeben habe: Es ist noch kein Knorpel aufgetreten. In der Occipitalregion und dem sich anschliessenden Rumpfteil gehört das vorderste Ganglion auf beiden Körperseiten zum Segment des 6. Myotomes. Vor demselben liegen 5 Myotome mit deutlichen Muskelfasern; die 4 hintersten auch mit je einer ventralen Wurzel. Dorsale Wurzeln und Ganglien fehlen.

Das vorderste dieser Myotome ist sehr niedrig; es wird vom Vagus ganz gedeckt und von dessen Ram. branchialis 1 gekreuzt. Es ist Myotom $V$ und gehört zum 6. Segment in der Reihe der Kopfsomite. Das folgende Myotom $W$ ist durch die Wurzelplatte des Vagus in zwei Stiicke geschnitten. Hinter dem dorsalen Stück, in welchem das Myocöl noch deutlich ist, steigen die noch ungeteilten drei folgenden Myotome $X, Y, Z$ auf. Es liegen also 4 Myotome mit ihren dorsalen Enden zwischen dem Vagus und dem ersten Myotom dessen ventrale Nervenwurzel sich einer dorsalen Wurzel mit Ganglion angeschlossen hat.

Dieser Nerv ist der erste, und nicht, wie GOODRICH glaubt, der zweite Spinalnerv. Das Ganglion und die dorsale Wurzel abortieren um die Zeit des Auftretens des Occipitalbogens (vgl. die 3. Anmerkung).

2) Ventral (basal) schliessen sich demselben, wenigstens bei Acanthias, Elemente eines ersten Wirbelkörpers an.

3) Auf einer neulich angefertigten Querschnittserie durch einen Embryo von Scyllium canicula von $29 \mathrm{~mm}$ Länge zeigt sich der Occipitalbogen als knorpeliger Auswuchs des Parachordale gerade aufgetreten und noch sehr niedrig. Hart am Vorderrande des Bogens tritt die letzte Hypoglossuswurzel $z$, noch nicht vom Knorpel umrandet, aus. Hinter dem Bogen tritt der erste Spinalnerv über das Ende des Parachordale. Auf der linken Körperseite hat der Nerv noch eine kräftige dorsale Wurzel mit gut ausgebildetem Ganglion, obgleich etwas kleiner als das Ganglion des zweiten Spinalnerven. Auf der rechten Körperseite aber ist das Ganglion verschwunden.

Auf einer Querschnittserie durch einen Embryo von $31 \frac{1}{2} \mathrm{~mm}$ Länge derselben Spezies ist die dorsale Wurzel des 1. Spinalnerven mit ihrem Ganglion auf beiden Körperseiten abortiert. Dies stimmt mit den Befunden von GooDRICH an etwas älteren Embryonen überein. 
lungsgeschichtlichen Gründen dieser Trennung beipflichten, denn auch in der Entstehung der Wirbelsäule finde ich bei Catulus stellaris viel primitivere Zustände als bei Scyllium canicula. Indem GoodRIcH das 4. Myotom gestrichen hat, verändert er die Numeration der metotischen Somite, so dass sein viertes Somit, das vom Glossopharyngeus gekreuzt wird, meinem fünften, sein fünftes Myotom (gekreuzt vom Ram. 1 vagi) meinem sechsten entspricht. Wenn ich ihn recht verstehe, hat er dies auf Seite 11 seiner Arbeit aber vergessen und bestreitet er mich, während wir vollkommen mit einander einverstanden sind.

\section{Mit Methylenblau behandelte Totalpräparate.}

Bevor wir zu der Skelettbeschreibung nach Schnittserien zurückkehren, bei welcher wir durch andre Organsysteme aufgehalten werden, wollen wir die Skelettentwicklung an den Totalpräparaten aus Helder, schliesslich an Präparaten aus Helgoland rasch überblicken.

Bei Embryonen von 22 bis $29 \mathrm{~mm}$ Länge ist das Parachordale mit seiner bald auftretenden Lamina basiotica in der Regel der einzige Skelettteil. Ausnahmsweise findet man auch eine schwache Verknorpelung an der Ohrkapsel.

Embryonen von 30 bis $33 \mathrm{~mm}$ Länge. In dieser kurzen Periode treten viele neue Knorpelteile auf, und zwar die folgenden: Palatoquadratum und Unterkiefer, der letztere in zwei Stücken, das proximale Stück in der Nähe des späteren Gelenkes, das distale in der Nähe der Symphysis. Weiter sieht man Ceratohyale, Hyomandibulare und Basihyale, Polknorpel und Trabecula. Zuletzt erscheinen Coracoid und Scapula.

Die Ohrkapsel erhält, abgesehen von der Lamina basiotica, zwei eigene Verknorpelungen, die eine am vorderen die andre am hinteren Pole der Kapsel. Sie entstehen an den Ampullen der Bogengänge, die eine, die Cartilago anterolateralis an den Ampullen des vorderen und lateralen Bogenganges, wächst bald kaudalwärts, die Aussenseite des lateralen Ganges deckend. Sie verlötet sich bald mit der etwas später an der Ampulle des hinteren Bogenganges entstehenden Cart. posterior.

In den freien Gliedmassen, den Wirbel- und Kiemenbogen ist noch keine deutliche Verknorpelung aufgetreten.

Palatoquadratum und Ceratohyale kommen bei allen Exemplaren vor, die übrigen Knorpel nur bei einem Teil, ohne dass eine bestimmte Reihenfolge nach den Längenmassen der Embryonen bemerkbar ist. Wohl kann man sagen, dass im Kieferbogen die Mandibula und im Hyoidbogen das Basihyale zuletzt entstehen.

Alle diese Teile treten selbständig auf und nicht wie die meisten Autoren vom Kiefer- und Zungenbeinbogen angeben, als Abgliederungen von einem früher einheitlichen Knorpelstab.

Bemerkenswert ist, dass die Knorpel im Kiefer- und Zungenbeinbogen kräftig ausgebildet sind bevor dieselben in den Kiemenbogen auftreten. Anders als im den Kiemenbogen sind sie wohl als Stützen in Anpassung an das Ergreifen und Verschlingen der Beute entstanden.

Wie schon SEWERTzoff hervorgehoben hat, findet nur das Vorderende des Palatoquadratums eine direkte Stütze am Hirnschädel (an der Trabecula). Das Hinterende dagegen ist durch das Spritzloch vom Neurocranium getrennt und findet seine Stütze nicht am (späteren) Postorbitalfortsatz, sondern am Hyoidbogen. Das Vorderende des Palatoquadratums in diesen Stadien ist der Proc. palatotrabecularis („palatobasalis").

Schon bei seinem Auftreten liegt das Palatoquadratum nicht senkrecht zur Körperachse wie die später erscheinenden Epibranchialia, sondern parallel zu derselben, wie man dies in Anpassung an die Nahrungsaufnahme auch erwarten sollte.

Die Verknorpelung des Hyomandibulare schreitet von unten nach oben ${ }^{1}$ ), bis an die Lamina basiotica des Parachordale hinauf.

1) Wenn diese Wachstumsweise der Anlage des Hyomandibulare allgemein bei den Fischen vorkommt, so wird die spätere verschiedene Lage desselben in bezug auf den Truncus hyoideo-mandibularis des Facialis begreiflich: Bei den Selachiern ist der Knorpel hinter dem Truncus bis zur Ohrkapsel hinaufgewachsen; bei den Knorpelganoiden vor dem Truncus. Bei Polypterus muss der Knorpel zwischen dem Ram. mandibularis und Ram. hyoideus hinaufgelangt sein. Bei Amia, Lepidosteus und Knochenfischen, wo das Hyomandibulare vom Truncus des Facialis durchbohrt ist, wird der Knorpel unter dem Nerven hinaufgewachsen sein und denselben mit seinem oberen Rande umschlossen haben. 
Der Occipitalbogen ist noch nicht ausgebildet. Beim Embryo von $33 \mathrm{~mm}$ Länge bemerkt man die Basis des Bogens als eine kleine Erhebung auf dem Hinterende des.Parachordale. Dieselbe trägt eine Rinne für die letzte Hypoglossuswurzel $z$ (weiter rostralwärts bemerkt man noch zwei seichtere Rinnen für die Wurzeln $y$ und $x$ ) und läuft vor und hinter der Rinne in eine kurze Spitze aus. Die beiden Spitzen können einen Doppelbogen vortäuschen.

Embryonen von 36 bis $43 \mathrm{~mm}$ Länge. Der Occipitalbogen ist jetzt ausgebildet und schon an der Basis durchlöchert (Embryonen von 34 und $35 \mathrm{~mm}$ Länge besitze ich nicht). Ein früheres Stadium desselben wird bei der nächsten Schnittserie beschrieben. Das platte Vorderende der Palatoquadratums ist noch der Proc. palato-trabecularis. Im Unterkiefer ist der proximale mit dem distalen Knorpel zu einem Stücke verschmolzen.

Die vom Trochlearis durchbohrte Cart. supraorbitalis und die Cart. antotica sind als selbständige Knorpel aufgetreten. Das selbständige Auftreten der Cart. antotica sieht man auf Schnittserien; die Totalpräparate machen aber den Eindruck, dass die Basis des Knorpels von Anfang an kontinuierlich mit dem Vorderende des Parachordale zusammenhänge, wie ich früher (1904) irrtümlich angegeben habe.

Die am meisten entwickelten Embryonen (von $43 \mathrm{~mm}$ Länge) zeigen folgendes: Die Trabekeln sind noch in ganzer Länge paarig, stehen aber im Begriffe sich bis zur Mitte der interorbitalen Region zu verlängern und sich hier berührend und unpaar. weiter wachsend die interorbitale Trabekelplatte zu bilden, der wir sofort bei den Helgoländer Embryonen begegnen werden, wo sie schön blau ist. Jetzt zeigt sie sich als ein hellgrauer Schimmer.

Der mediane Schlitz zwischen den Trabekeln setzt sich kaudalwärts in das rundliche eigentliche Polfenster fort. In der Mitte desselben ist aber bei einigen Exemplaren ein selbständiger Knorpelkern aufgetreten, auf den wir noch zurückkommen werden.

Im vordersten Kiemenbogen, oder auch in den beiden vordersten, sind Cerato-, Epi- und Pharyngobranchiale als selbständige Knorpelstücke erschienen.

Die Wirbelsäule zeigt sich als eine sehr dünne, graue paarige Platte, die der Seitenwand der Chorda anliegt. Dieselbe erstreckt sich von der Schädelanlage, mit der sie kontinuierlich zusammenhängt, bis in den Schwanz hinein und ist mit regelmässig abwechselnden helleren und dunkleren Querbändern versehen. Den oberen und den unteren Rand der Platte bildet ein feiner blauer Knorpelstreifen in welchem die oberen und unteren Bogenbasen als etwas verdickte Stellen kenntlich sind. Die dunkleren Querbänder verbinden die Basen je eines unteren und oberen Bogens.

Unmittelbar hinter dem Kopfe sieht man einige wenige Intercalaria als selbständige Knorpelstückchen.

Hier sind auch die oberen Bogenbasen am stärksten entwickelt. Doch ist noch keine so weit hinaufgewachsen, dass sie eine Rinne zur Aufnahme der zugehörigen ventralen Nervenwurzel bildet. Die stärksten unteren Bogen findet man dagegen im Schwanze, wo sie mit denjenigen der andren Körperseite zu schmalen, ventralen Dornfortsätzen verschmolzen sind.

Coracoid und Scapula sind noch getrennt. In der Brust- und Bauchflosse, sowie in beiden Rückenflossen stehen Knorpel im Begriffe aufzutreten; die Anlagen haben aber noch keine deutlich blaue Farbe angenommen.

Embryonen von nur $40 \mathrm{~mm}$ Länge aus Helgoland, die ich vor vielen Jahren zu gleicher Zeit mit den so eben behandelten aus Helder in Canadabalsam eingeschlossen habe, sind viel weiter entwickelt. Ihr Kopfskelett ist mehr vorgeschritten als dasjenige dessen Modell auf Fig. $3 a$ und $3 b$, Taf. XI abgebildet wurde. Die Cart. supraorbitalis ist mit der Cart. antotica zum Pleurosphenoidknorpel verschmolzen, dessen Basis jetzt - wie Schnitte zeigen - mit dem Vorderende des Parachordale verlötet ist.

Die Trabekeln sind über die Mitte der Interorbitalregion vorgewachsen und bilden hier die so eben erwähnte unpaare Trabekelplatte, welche die vordere Hälfte der Interorbitalregion einnimmt. Der Vorderrand dieser Platte setzt sich lateralwärts in die Lamina orbitonasalis (Ethmoidknorpel, SEwERTZOFF) zwischen Auge und Nase fort. Von der Mitte des Vorderrandes geht der unpaare mediane Rostralstab ab der, zwischen den Nasengruben unter dem Vorderhirn verlaufend, vorn frei endet. Da mir Zwischenstadien fehlen, konnte ich nicht beobachten, ob die Lamina orbitonasalis und der Rostralstab selbständig angelegt werden oder nicht. SEwERTzoff gibt für die Lamina (Ethmoidknorpel) eine selbständige Anlage an, fand aber $(1899$, p. 312$)$ dass sie bei Pristiurus keine selbständige Bildung ist.

Der viereckige Orbitalrahmen, durch welchen der Opticus und Oculomotorius hinaustreten, ist 
bei einigen Embryonen geschlossen, indem sich an der vorderen oberen Ecke die Enden der Lamina orbitonasalis und des Pleurosphenoidknorpels vereinigt haben. Bei andern Exemplaren besteht hier noch eine kleine Lücke. Die untere Seite des Orbitalrahmens wird von der Trabekel, die vordere Seite von der Lamina orbitonasalis. die hintere und obere Seite werden vom Pleurosphenoidknorpel (der an der Stelle der früheren Cart. supraorbitalis den Trochlearis durchlässt) gebildet.

Der supraorbitale Teil des Sphenoidknorpels ist nach hinten bis an die Ohrkapsel gewachsen und hat so die Incisura antotica (durch welche Trigeminus, Facialis und Abducens hinaustreten) zum Foramen geschlossen.

Die Ohrkapsel ist jetzt so weit kaudalwärts gewachsen, dass ihr Hinterrand mit dem Hinterrand des Occipitalbogens in derselben Querebene liegt. Ihr Vorderrand liegt im Niveau der Stelle wo die Trabekel und der Pleurosphenoidknorpel mit dem Parachordale verwachsen sind. Mit andern Worten: die Ohrkapsel hat die gleiche Länge erreicht wie das Parachordale, das sie nach aussen vollständig deckt.

Das Palatoquadratum endet nicht mehr am proc. palato-trabecularis (GARMAN) sondern setzt sich von hier verschmälert rostralwärts fort und läuft in eine Spitze aus, welche diejenige der andern Seite fast berührt.

Der vordere Oberlippenknorpel und ein Spritzlochknorpel sind aufgetreten.

Der Kiemenbogenapparat hat die Form des erwachsenen; die Epi- und Ceratobranchialia der vier vorderen Bogen sind aber durchlöchert. Einige Kiemenstrahlen und Extrabranchialia („äussere Bogen") sind knorpelig.

Der Schultergürtel ist ein kräftiger Knorpel, der an seinem Gipfel das selbständig auftretende Suprascapulare trägt. Scapula und Coracoid sind nicht nur vollständig mit einander verschmolzen, sondern beide Schultergürtelhälften gehen in der ventralen Medianlinie schon kontinuierlich in einander uiber. In den freien paarigen Extremitäten sind die Basalia, zum Teil auch die Radialia deutlich knorpelig und in beiden Rückenflossen stimmt das Skelett, der Hauptsache nach, mit demjenigen des erwachsenen Tieres überein. Das Skelett der Rückenflossen ist aber noch weit entfernt ${ }^{1}$ ) von der Wirbelsäule, der es später zum Teil anliegt. Dasselbe entsteht selbständig und kann nicht als ein Derivat des Achsenskeletts betrachtet werden. Im dorsalen Abschnitt der Schwanzflosse sind selbständige knorpelige Flossenstrahlen aufgetreten, während der ventrale Abschnitt von den kräftigen Dornfortsätzen der unteren Bogen gestützt wird.

An der Wirbelsäule sind die Basen der oberen Bogen so weit emporgewachsen, dass sie je eine Rinne für die zugehörige ventrale Nervenwurzel aufweisen. Dorsale Intercalaria finden sich nur in geringer Zahl hinter dem Kopfe. Ihre Reihe erreicht die Region des Schultergürtels noch nicht. Das vorderste dieser selbständigen Knorpelstücke ist das grösste; kaudalwärts nimmt ihr Umfang regelmässig $a b$, so dass das hinterste Intercalare unter dem Binocularmikroskop als ein blauer Punkt zwischen zwei Bogenbasen erscheint.

Verfolgt man die Reihe von hinten nach vorn, so sieht man wie die Intercalaria allmählich beträchtlich über das Niveau der Bogenbasen hinaufwachsen. Das vorderste Intercalare reicht fast eben so hoch hinauf wie der Occipitalbogen. Wir kommen im nächsten Kapitel auf diesen Punkt zurück.

\section{Querschnittserie durch einen Embryo von $28 \mathrm{~m}$ m Länge.}

Modell Fig. $2 a$ und $2 b$, Taf. XI, Textfig. 1.

Es lag mir daran eine Querschnittserie zu besitzen durch einen Embryo bei welchem der Occipitalbogen gerade verknorpelt war. $Z$ u diesem $Z$ wecke wurden nach einander Schnittserien angefertigt durch Sommerembryonen aus Helgoland von $321 / 2,301 / 2$ und $291 / 2 \mathrm{~mm}$ Länge, die sämtlich den Bogen, schon durchbohrt und bis zur oberen Spitze knorpelig zeigten. Erst bei einem Exemplar von $28 \mathrm{~mm}$. Länge gelangte ich zum Ziel. Dasselbe ist in Betreff des Occipitalbogens ein wenig weiter entwickelt als dasjenige von $33 \mathrm{~mm}$. Länge aus Helder.

Während des kurzen Intervalles van 28 bis $32 \frac{1}{2}$ mm Länge entwickelt sich das Kopfskelett der Helgoländer Embryonen beträchtlich weiter. Wir wollen das Stadium von $28 \mathrm{~mm}$, von dessen Skelett ein Modell angefertigt wurde, ausführlicher behandeln und können dann mit den übrigen Stadien kürzer verfahren.

1) Ähnliches zeigen $40 \mathrm{~mm}$ lange Embryonen von Torpedo ocellata. 
Die Prämandibularhöhle der ersten Somites ist nun völlig verschwunden. In der Basis des Mittelhirnpolsters liegt noch der Chordahaken, das unpaare verdichtete Gewebe umgreifend, das wir im 1. Kapitel als "Mittelstück” erwähnt haben. Ich will dasselbe aḱrochordales Gewebe nennen, weil es, obgleich bei Acanthias niemals verknorpelnd, doch wegen seiner Lage am Chordahaken in der Basis des Hirnpolsters, zum Teil der Cart. acrochordalis homolog sein muss, welche SonIEs (1907) bei Vogelembryonen entdeckt hat. Bei denselben ist dieser Knorpel sogar der erste der überhaupt im Körper auftritt. Bei Acanthias bildet das akrochordale Gewebe ein Polster, welches das Infundibulum mit der Hypophysis von hinten her stützt und sich fast in deren ganzen Breite erstreckt, wie man am besten auf Frontalschnitten sieht (vgl. Kap. 5, Textfig. 2 aus einem etwas älteren Stadium).

Die Querschnitte welche dieses Polster treffen, zeigen lateral den Pleurosphenoidknorpel, der durch die Verschmelzung der Cart. antotica mit der Cart. supraorbitalis entstanden ist. Er bildet, wie erwähnt, die hintere und die dorsale Begrenzung des späteren Orbitalrahmens. Die vordere Begrenzung (die Lamina orbitonasalis) fehlt noch ganz und die untere, welche von dem Polknorpel und der Trabekel gebildet wird, ist jetzt nur ganz hinten vorhanden, da die letztere noch nicht weit rostralwärts vorgewachsen ist.

Eine schmale Spalte in der früheren Cart. supraorbitalis lässt den N. trochlearis in die spätere Orbita treten. Weiter rückwärts tritt der N. oculomotorius in dieselbe, hart am Vorderrande der früheren Cart. antotica. Die Cart. antotica scheint in der Entwicklung des Schädels von Lepidosteus (VeIt) und Amia (Pehrson) zu fehlen; die Cart. supraorbitalis ist aber vorhanden und wird, wenigstens bei Amia, noch als selbständiger Knorpel angelegt.

Der Parachordalknorpel reicht jetzt eine kurze Strecke vor der Ohrkapsel. Das Bindegewebe, welches seine vordere Spitze umgibt, geht rostralwärts ohne scharfe Grenze in das akrochordale Gewebe über. Der Querschnitt welcher die vordere Spitze das Parachorchale trifft, zeigt auch das hintere Ende des Pleurosphenoidknorpels. Diese beiden Knorpel berühren hier einander fast, sind aber doch deutlich getrennt, was ich (1904) durch die Überlagerung der Teile an meinen Totalpräparaten nicht wahrnehmen konnte. SEWERTZOFF hatte also Recht als er die selbständige Anlage des "Alisphenoidknorpels" beschrieb und GOODRICH (1918) konnte dies bei Scyllium canicula bestätigen. SONIES (1907) fand die selbständige Anlage der Cart. antotica beim Hühnchen, wo es sich später mit dem Akrochordale verlötet. Bei Selachiern verlötet es sich dagegen etwas mehr nach rückwärts mit dem vorderen Ende des Parachordale (sieh weiter unten) während es im vorknorpeligen Zustand (sieh oben) vom akrochordalen Gewebe ausging, und auch später noch an der Verlötungsstelle mit demiselben zusammenhängt.

Auf einem hart hinter dem N. opticus geführten Querschnitt sehen wir die vordere Spitze des Parachordale sowie das vordere Ende der jetzt noch paarigen Trabecula. Verfolgen wir die Serie nach rückwärts, so zeigt sich das Infundibulum mit der Hypophysis eingeschlossen zwischen den Parachordalia (mit der Chorda zwischen sich) und den Trabekeln. Die Parachordalia liegen dorsal, die Trabekeln ventral vom Infundibulum.

SEWERTZOFF hat schon gefunden, dass die Trabekeln zufolge der Mittelhirnbeuge bei Acanthias anfangs senkrecht zur Körperachse stehen, dass sie aber später, beim Eintreten der Brückenbeuge allmählich, wie bei andern Tieren, parallel zur Achse gestellt werden. Bei Scyllium kommt nach GOODRICH die senkrechte Stellung nicht vor und ich kann ihm nach meinen Scylliumpräparaten darin beistimmen. Wenn wir am hinteren Ende der Hypophysis angelangt sind, tritt plötzlich hinter der Trabekel eine kleine paarige, viereckige Platte auf, der Polknorpel, der senkrecht auf das Parachordale trifft. Derselbe wurde von NoordenBos (1904) beim Kaninchen entdeckt, wo er mit Parachordale und Trabekel in gleicher, frontaler Ebene liegt und mit denselben das Polfenster (Hypophysenfenster) begrenzt, das am vorderen Ende der Körperachse liegt.

Ich fand dieses Element (1904) bei Acanthias, SonIES (1907) bei Vögeln und VĖT (1911) bei Lepidosteus. Bei Amphibien konnte PeEters (1910) keinen selbständigen Polknorpel auffinden.

Der M. obliquus externus entspringt vom Parachordale gerade über dem Polknorpel ohne an demselben befestigt zu sein.

Das jederseits von den drei erwähnten Knorpeln begrenzte Polfenster ist eine weite, senkrecht zur Körperachse stehende, fast ringförmige Öffnung, die sich ventralwärts (morphologisch : rostralwärts). 
zwischen den Trabekeln als schmaler Spalt fortsetzt. Das Fenster wird grossenteils von Mesenchym eingenommen. Von hinten her tritt die paarige Carotis interna (C. posterior) durch dasselbe und vereinigt sich mit derjenigen der andern Körperseite zu einem kurzen, unpaaren Stamm, der sich rostralwärts bald in zwei Gabelzweige spaltet. Jeder Gabelzweig tritt vor dem vorderen Rande des Polknorpels lateralwärts und vereinigt sich dann mit der Carotis spiracularis (C. anterior) welche kurz vorher die Art. ophthalmica magna an den Augapfel abgegeben hat. Die Richtung der Blutstroms ist aus der Weite der Gefässe erkennbar: Die Carotis interna und spiracularis sind enger als der durch ihre Vereinigung gebildete Stamm. Derselbe gibt eine Art. ophthalmica ab, die mit dem N. opticus in den Augapfel tritt und als Art. hyaloidea (centralis retinae) aufzufassen ist. Darauf steigt der Stamm an der rostralen Grenze des Mittelhirnpolsters bis zu dessen Gipfel hinauf, wo er umbiegt und an der kaudalen Grenze der Polsters wieder hinuntertritt. Dann verschmilzt die Arterie, wie RaffaEle gefuńden hat, mit derjenigen der andern Körperseite zur weiten Art. basilaris, die an der ventralen Fläche der Rhombencephalons spinalwärts verläuft.

Im Polfenster bemerkt man, abgesehen von der Carotis interna, auch den engen Hypophysengang, der noch in ganzer Länge vorhanden ist aber sein Lumen zum Teil verloren hat. Er zieht durch das Polfenster kaudalwärts und mündet in den vorderen Teil der Mundhöhle aus. Durch den vorderen schmalen Spalt zwischen den Trabekeln tritt eine Vene aus dem die

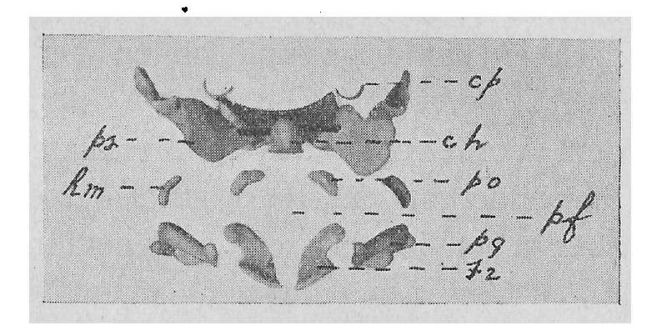

Fig. 1. Vorderansicht des Modelles der Taf. XI, Fig. $2 a$ und $2 b$. Buchstabenerklärung am Schluss der Arbeit. Hypophysis umspinnenden Plexus.

Am ventralen Rande des Polfensters erreicht das vordere Ende des Palatoquadratums das hintere Ende der Trabekel. Wir wollen aber das Neurocranium erst weiter besprechen, um dann zum Splanchnocranium überzugehen.

Die Ohrkapsel ist noch keine einheitliche Knorpelbildung. Der anterolaterale Knorpel ist zwar hart hinter der Wurzel des Acustico-facialis mit der Lamina basiotica des Parachordale verwachsen, der hintere Ohrknorpel ist aber noch allseitig frei und liegt auf einer dicken Mesenchymschichte, die von dem Hinterende der Lamina basiotica gestützt wird. Durch diese Mesenchymschichte tritt der N. glossopharyngeus hinaus. Die Canales semicirculares sind noch nicht in der Gestalt von Kanälen, sondern als platte Auswüchse der epithelialen Ohrblase vorhanden. Als erste Andeutung der medialen Kapselwand erhebt sich unmittelbar hinter der Eintrittsstelle des N. acusticus ein kleiner, sagittaler, dreieckiger Fortsatz vom Körper des Parachordale an der Abgangsstelle der Lamina basiotica.

Durch die weite, dorsalwärts offene Incisura antotica treten die Nn. trigeminus, facialis und abducens hinaus. Der hintere Rand dieser Incisur wird von der Ohrkapsel, der vordere Rand vom Pleurosphenoidknorpel und der ventrale Rand vom Parachordale gebildet.

Das Parachordale ist noch in ganzer Länge paarig. Noch nirgends ist die dorsale oder ventrale Fläche der Chorda von Knorpel überwachsen, wie dies auch im Rumpfe nicht der Fall ist. Die collagene Chordascheide ist im Kopfe wie im Rumpfe frei von Zellen und Knorpel. Am hinteren Ende der Ohrkapsel setzt sich das Parachordale als dicke Knorpelplatte, die ganze Höhe der Chorda einnehmend, kaudalwärts fort. Dasselbe entsendet unmittelbar hinter der letzten Hypoglossuswurzel $z$ den jetzt gerade knorpeligen Occipitalbogen, auf den wir sofort zurückkommen, der diese Wurzel noch nicht umschliesst. Unter diesem Bogen verschmälert sich dás Parachordale zu einer dünnen Platte, die als solche mit dem Ende des Bogens aufhört. Von der Platte gehen aber an jeder Korperseite zwei Knorpelstreifen längs der Chorda kaudalwärts $a b$, an denen die Anlagen der oberen und unteren Bogen als kleine Verdickungen hervortreten. Die Anlagen der unteren Bogen sind auf dem Querschnitt, viel schmächtiger als diejenigen der oberen Bogen.

Die Knorpelstreifen entstehen in den beiden paarigen zelligen Leisten, welche BALFour (1878, p. 151) bei Scyllium im Stadium $L$ auftreten sah. Er fand, dass die Bogen im Stadium $N$ angefangen sind $z u$ chondrifizieren, spricht aber nicht von einem knorpeligen Zusammenhang. Auch spätere Untersucher glauben, dass die "oberen und unteren Bogen" als selbständige Stücke angelegt werden. Bei spezifischer Färbung (z.B. mit Methylen- oder Victoriablau) sieht man aber leicht, dass es sich um vier kontinuierliche Knorpelstreifen, Basalstreifen, handelt, die offenbar zur Verstärkung der Chorda 
dienen und deren Elastica direkt aufliegen. Bei Scylliumembryonen von $22 \mathrm{~mm}$ Länge finde ich diese Knorpelstreifen schon. Sie erstrecken sich bis in den Schwanz hinein. Der dorsale und der ventrale Basalstreifen sind im Schädel von Anfang an zum Parachordale verschmolzen. Im Rumpfe zerfallen sie später, wohl in Folge des Chordawachstums und des Muskelzuges in die Reihe der dorsalen und ventralen Basalia (sog. oberen und unteren Bogen). Die Beziehung derselben zu den Basen (Körper, Zentren) der Wirbel ist primär. Bei Acanthias wachsen die dorsalen Basalia secundär zu Neuralbogen aus. Bei Scyllium sind diese Verhältnisse etwas komplizierter, doch kann ich hier darauf nicht eingehen.

Schon in diesem frühen Stadium ist der erste obere Bogen, über welchem die ventrale Wurzel des 1. Spinalnerven hinaustritt, mit dem unteren an der Seite der Chorda verschmolzen. Die Verschmelzungslamelle ist aber nur eine Knorpelzelle dick. Die übrigen oberen Bogen hängen mit den unteren noch nicht zusammen. Unmittelbar über denselben tritt je eine ventrale Nervenwurzel, die nachher von vorn und hinten her vom Knorpel umfasst wird, so dass sie dann durch ein Loch im Bogen hervortritt. Die dorsale Wurzel des 1. Spinalnerven tritt etwas hinter der ventralen Wurzel vor dem Vorderrande des 1. Intercalare des Rumpfes, das in der Regel zeitlebens selbständig bleibt, aus. Sie bildet an der Aussenseite desselben ein noch kräftiges Ganglion, das durch seine buckelige Form aber schon Zeichen der Degeneration aufweist.

Von den (dorsalen) Intercalarien zeigen nur die 4 vordersten Knorpelbildung. Dieselbe nimmt in kaudaler Richtung ab und das 4. Intercalare weist nur noch einen unscheinbaren Knorpelkern auf. Die Intercalarien werden nicht wie die Bogen als Verdickungen eines kontinuierlichen Knorpelstreifens angelegt, sondern treten als selbständige Knorpelherde auf. Ventrale Intercalarien sind nicht vorhanden.

Dass der Occipitalbogen, auf den wir jetzt zurückkommen, erst ganz kürzlich verknorpelt ist, sieht man an seiner geringen Blaufärbung und auch daran, dass er die vor ihm austretende letzte Hypoglossuswurzel noch nicht umschliesst. Für die Auffassung der morphologischen Bedeutung des Bogens ist es bemerkenswert, dass derselbe auf beiden Körperseiten ein wenig verschieden entwickelt ist. Derjenige der rechten Seite ist einheitlich und erhebt sich mit breiter Basis vom hinteren Teile des Parachordale mit dem er kontinuierlich zusammenhängt. Der linke Bogen aber besteht aus zwei hinter einander liegenden Teilen, die an einer kleinen Stelle gerade angefangen sind zu verschmelzen und erst nach der Verschmelzung das Gegenstück des rechten Bogens bilden würden. Der vordere Teil erhebt sich zwar gleichfalls mit breiter Basis vom Ende des Parachordale, bleibt aber niedrig, über ihn tritt die letzte Hypoglossuswurzel hinaus. Seinem kaudalen Rande ist der hintere Teil angefügt, der bis in die entsprechende Höhe des rechten Bogens hinaufreicht, ventralwärts aber durch eine ziemlich breite Spalte vom Parachordale getrennt wird, also kein Auswuchs desselben sein kann. Dieser hintere Teil hat die Gestalt eines Intercalare und würde nach Form und Grösse vollkommen in die Reihe der Intercalarien passen, die von hinten nach vorn regelmässig an Umfang zunehmen.

Der Occipitalbogen von Acanthias ist also aufzufassen als ein Bogen, der mit dem darauffolgenden Intercalare des Schädels zu einem Ganzen verschmolzen ist.

Die Accessoriuswurzel des Vagus erreicht das Ganglion des 1. Spinalnerven nicht mehr, sondern endet kurz vor demselben. Auf der linken Körperseite hängt an der Innenfläche des Occipitalbogens noch das sehr rudimentäre, zu der letzten Hypoglossuswurzel gehörige Ganglion $z^{d}$ von ihr herab, das später verödet. Würde sich das Ganglion erhalten, so müsste es in den Schädelraum eingeschlossen werden, während die Spinalganglien bekanntlich ausserhalb der Wirbelsäule liegen. Auch setzt sich das Ganglion nicht in, einen peripheren Nerven fort. Wäre dies den Fall, so müsste der Nerv den Occipitalbogen durchbohren.

Auf der rechtem Körperseite zeigt die Accessoriuswurzel statt eines herabhängenden Ganglions nur eine kleine zellige Verdickung.

Der Hypoglossus besitzt rechts und links drei Wurzeln: $x, y, z$. Die Wurzel $x$, welche beim Embryo vom $24 \mathrm{~mm}$ Länge schon abortiert war, ist schwach und besteht nur aus einem einzigen Bündel, das beim Austritt aus dem Gehirn nur auf einem Schnitt sichtbar ist. Die zweite Wurzel $y$ entspringt links mit drei, rechts mit zwei Bündeln. Jedes ist beim Austritt nur auf einem Schnitt sichtbar. Die dritte Wurzel $z$ entspringt auf .der linken Seite mit drei Bündeln, je auf einem Schnitt sichtbar, auf der rechten mit zwei Bündêln, von denen das vordere auf drei Schnitten zu sehen ist. Zwischen zwei aufeinanderfolgenden Bündeln liegen 1 bis 2 Schnitte ohne Nervenaustritt. 
Für das Verständnis eines folgenden Embryos ist es wichtig, dass sämtliche Hypoglossuswurzeln noch hinter der Region der Ohrkapsel liegen.

Sie treten, wie auch der Glossopharyngeus und Vagus, durch die weite Incisura metotica, welche dorsal offen ist, hinten vom Occipitalbogen, unten vom Parachordale und vorn von der Ohrkapsel begrenzt wird.

Die Ohrkapsel hat den Glossopharyngeus schon überwachsen und wird für denselben später einen eigenen Knorpelkanal bilden.

Splanchnocranium. In den eigentlichen Kiemenbogen fehlt noch jede Knorpelbildung. In den beiden vordersten Visceralbogen sind aber die typischen Knorpelteile aufgetreten. Dieselben entstehen selbständig. Ein ursprünglicher knorpelige Zusammenhang mit nachfolgender Trennung, wie von mehreren Autoren angegeben wird, existiert nicht. Im Hyalbogen findet man das Hyomandibulare, Ceratohyale und Basihyale.

Im Kieferbogen berührt das Paḷatoquadratum, wie erwähnt, mit seinem vorderen Ende das hintere Ende der Trabecula. Bei flüchtigem Durchmustern der Schnittserie glaubt man, dass im Unterkiefer noch kein Knorpel vorhanden sei. Bei genauerem Zusehen bemerkt man aber, dass die beiden Knorpelherde in jeder Unterkieferhälfte, gerade aufgetreten sind.

Diese Bildungsweise der Mandibel, die auch bei Vogelembryonen vorkommt, ist interessant da. der Unterkiefer bei Acanthoden jederseits auch aus zwei Stücken zusammengesetzt war.

Auch im Schultergürtel sind beide Knorpelherde (Coracoid und Scapula) gerade aufgetreten. In der freien Extremität ist noch kein Knorpel vorhanden.

\section{Querschnittserien durch Embryonen von $29 \frac{1}{2}, 30^{1 / 2}$ und $32 \frac{1}{2} \mathrm{~mm}$ Länge.}

Diese Helgoländer Embryonen weisen fortschreitende Entwicklungsstadien des Skeletts auf, die wir hauptsächlich bei dem an weitesten vorgeschrittenen Embryo von $32 \%$ mm Länge kurz besprechen wollen. Es scheint nicht nötig jedesmal dabei anzugeben, ob die Veränderung schon in einem der beiden früheren Stadien aufgetreten ist oder nicht.

Das akrochordale Polster des Infundibulums am Chordahaken in der Basis des Mittelhirnpolsters ist, obgleich ohne umhüllende Membran, doch scharf von dem umgebenden lockeren Mesenchym abgegrenzt.

Sein Ursprung an der Chorda wächst kaudalwärts und hat bei einem Embryo von $35 \mathrm{~mm}$ Länge das Vorderende des Parachordale erreicht, während der Chordahaken angefangen ist sich aus dem Polster frei zu machen. Auf dem abgebildeten Frontalschnitt (Textfig. 2) sticht das rote Polster scharf gegen das blaue Parachordale ab, was durch die Photographie nicht wiedergegeben werden konnte.

Bei der gebraüchlichen reinen Kernfärbung sieht man das Polster kaum. Auch ist es bei Scyllium und Mustelus - soweit meine Beobachtungen reichen viel weniger entwickelt als bei Acanthias.

In der Pleurosphenoidplatte ist der Schlitz für den Durchtritt des Trochlearis zu einem Foramen geschlossen. Die Platte ist noch nicht mit dem Parachordale verwachsen.

Die dorsoventral abgeplatteten Trabekeln reichen nur ein paar Schnitte vor dem N: opticus und bilden hier die von Anfang an unpaare Trabekelplatte. Der

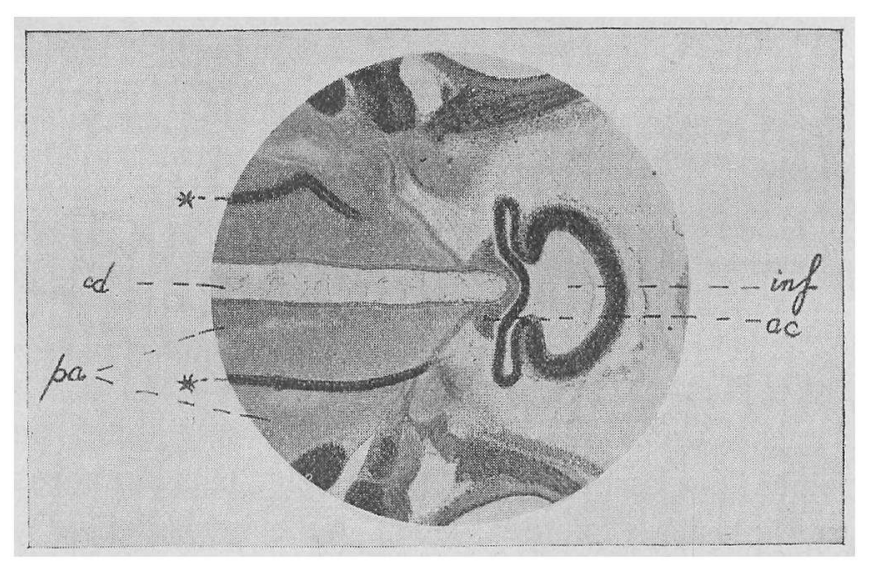

Fg. 2. Frontalschnitt durch die Chorda und das akrochordale Polster eines Embryos von $35 \mathrm{~mm}$ Länge. $\mathrm{cd}=$ Chorda; a $\mathrm{c}=$ akrochordales Polster $;$ inf. $=$ infundibulum; $\mathrm{pa}=$ parachordale; *.Falten, beim Schneiden im Parachordalknorpel gebildet.

Vorderrand dieser quer gestellten Platte setzt sich seitlich fort in die noch prochondrale Anlage der Lamina orbitonasalis zwischen Auge und Nasengrube. Von der Mitte dieses Vorderrandes geht der gleichfalls prochondrale, mediane Rostralstab zwischen den noch knorpelfreien Nasengruben nach vorn ab. Hinter dem N. opticus sind die Trabekeln paarig wie früher. 
Die Trabekeln sind wohl als Stützen des Prosencephalons entstanden und liegen morphologisch vor der Schädelbasis, die mit der Chordaspitze am Infundibulum endet. Die Ausdrücke "tropibasisch" und "platybasisch" sind morphologisch nicht richtig und könnten etwa durch "tropitrabisch" und „platytrabisch" ersetzt werden.

Der Polknorpel hat seine Selbständigkeit eingebüsst (bei den Exemplaren von $291_{2}$ und $301 / 2 \mathrm{~mm}$ Länge noch nicht). Sein unterer Rand ist nämlich mit dem Hinterrande der Trabekel verschmolzen. Sein oberer Rand ist noch frei, steht aber im Begriffe sich mit dem Parachordale zu verlöten.

Der Parachordalknorpel stösst jetzt, wie erwähnt, mit seinem schmalen vorderen Ende an den Hinterrand des akrochordalen Polsters. Hier liegt ihm auch das von oben herkommende kaudale Ende des Pleurosphenoidknorpels an. Ein paar Schnitte weiter kaudalwärts stösst der von unten herkommende Polknorpel an das Parachordale. Der Occipitalbogen ist, auch bei den Embryonen von 291.2 und $30^{1} / 2 \mathrm{~mm}$ Länge, zum Durchlass der letzten Hypoglossuswurzel durchlöchert.

In der Region vor den Ohrkapsel ist die collagene Chordascheide noch ganz frei von Knorpel und Zellen. In der otischen und auch in der occipitalen Region aber sieht man Zellen und blaue Knorpelgrundsubstanz, von den Parachordalia ausgehend, in die periphere Schichte der collagenen

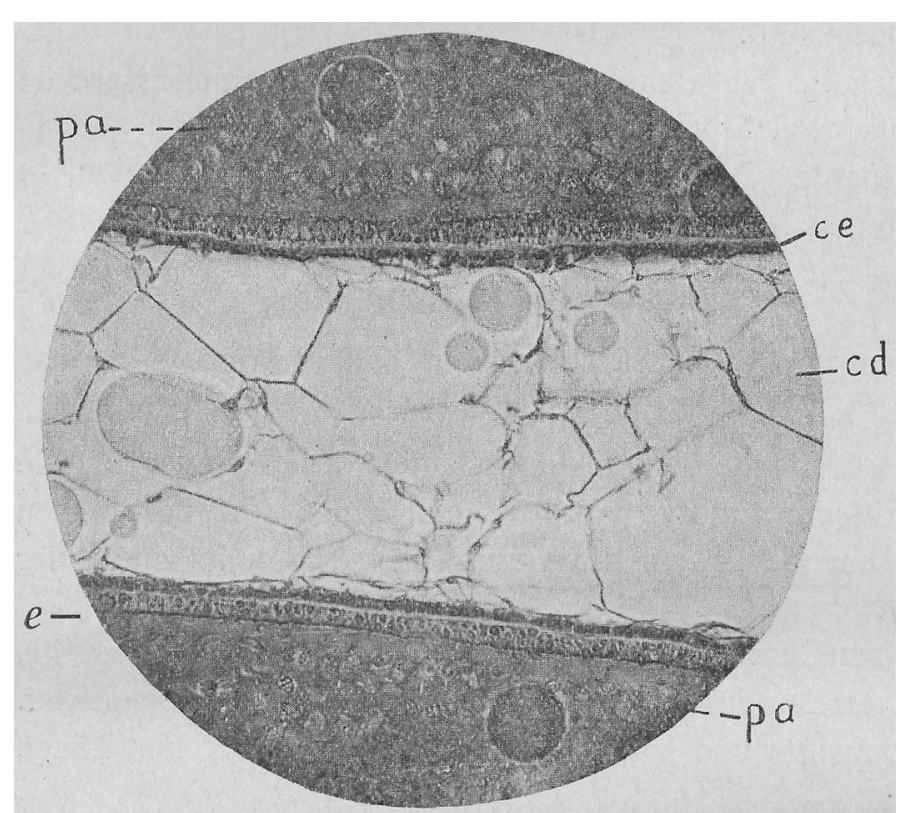

Fig. 3. Ein Teil des Schnittes der Textfig. 2 bei starker Vergrösserung; $\mathrm{ce}=$ Chordaepithel ; $\mathrm{cd}=$ chorda dorsalis ; $\mathrm{e}=$ Elastica $; \mathrm{pa}=$ Parachordalknorpel. Die grösseren Kreise in der Figur rühren von Tropfen her, die sich im Balsam gebildet haben. Das Eindringen der Knorpelgrundsubstanz in die Chordascheide ist auf der Zinkographie unkennntlich geworden.
Scheide eindringen und dieselbe allseitig - auch dorsal und ventral - umwachsen. Der ausserhalb der Scheide liegende Teil des Parachordale lässt die dorsale und ventrale Fläche der Chorda noch frei.

Das Parachordale ist ausserhalb der Elastica also in ganzer Länge noch paarig; die collagene Chordascheide ist rostral von der Ohrkapsel nicht verknorpelt. Der knorpelige Hohlcylinder, der die Chorda in der otischen und occipitalen Region umgibt, setzt sich kontinuierlich in den Rumpf, wenigstens bis zum 8. Wirbelbogen fort (weiter wurde nicht geschnitten). Auch am Rumpfe treten Zellen und Knorpelgrundsubstanz die von den Basalstreifen ausgehen, in die Chordascheide. Der Knorpel geht auch hier die Chorda ringsum umwachsen. Stellen wo dieselbe ringförmig vom Knorpel umgeben ist, wechseln mit solchen, wo der dorsale oder der ventrale Chordarand noch knorpelfrei ist, ab. Das Eindringen der Knorpelgrundsubstanz in die Chordascheide wurde, so viel ich weiss, noch nicht beobachtet; es ist bei der spezifischen Blaufärbung derselben aber fast auf jedem Querschnitt leicht zu sehen. Die von den mit spärlichem Protoplasma umgebenen roten Kernen siebartig durchlöcherte Grundsubstanz der Bogen schiebt sich mit groben, kurzen Fortsätzen durch die Elastica, welche trotz ihres homogenen Aussehens wohl aus einem Netzwerk von feinen elastischen Fibrillen besteht. Die Grundsubstanz muss beim Eindringen ihre Starrheit verlieren und plastisch werden, denn sie wird aufgelöst in feine blaue Lameilen zwischen den konzentrisch angeordneten Zellen der collagenen Chordascheide.

Es wird nun fraglich, ob bei jüngeren Embryonen nicht auch die collagene Substanz (vielleicht in flüssiger Form) durch die Elastica gedrungen sei. Er wäre denkbar, dass das Chordaepithel dazu diene - nicht um die collagene Substanz abzuscheiden, sondern um zu verhüten, dass dieselbe zu weit in die Chorda hineindringe.

Die Ohrblase ist beträchtlich weiter entwickelt als beim Exemplar von $281 / 2 \mathrm{~mm} \mathrm{Länge.} \mathrm{Die}$ Canales semicirculares sind nun sämtlich als Kanäle vorhanden. Die Cart. anterolateralis ist mit der Cart. posterior verschmolzen. Die laterale Wand der Ohrkapsel ist eine Schale, welche auch den vorderen und hinteren Pol derselben umfasst. 
Der Boden der Kapsel wird von der Lamina basiotica des Parachordale gebildet, welche in beträchtlicher Ausdehnung mit dem ventralen Rande der Knorpelschale verwachsen ist. Die Kapsel zeigt sich auf 131 Schnitten. Die Verwachsungsstelle mit der Lamina basiotica wird auf 70 Schnitten getroffen; 29 Schnitte liegen vor und 32 hinter dieser Stelle. Die Kapsel ist also über mehr als die Hälfte ihrer Länge mit dem Parachordale verlötet und ist vorn ungefähr gleichlang frei (29 Schnitte) wie hinten (32 Schnitte).

Das rostrale Ende der Lamina basiotica fällt mit demjenigen der Verwachsungsstelle zusammen und liegt nur drei Schnitte hinter dem Hervortreten des Facialis. Das kaudale Ende der Lamina basiotica erstreckt sich dagegen viel weiter nach rückwärts als das Hinterende der Verwachsungsstelle, fast ebenso weit wie die Ohrkapsel selbst.

Der N. glossopharyngeus durchkreuzt des Gebiet der Ohrkapsel zwischen dem Can. semic. posterior und dem Sacculus, ist aber noch nicht knorpelig getrennt von der Incisura metotica, welche auch den Vagus und die vordere Wurzel $y$ des Hypoglossus hindurchtreten lässt.

Die Accessoriuswurzel des Vagus endet noch kurz vor dem ersten Spinalganglion, besitzt aber auf beiden Körperseiten keine Anlagen mehr als Reste dorsaler Hypoglossusganglien.

Der Hypoglossus, auf den wir sofort zurückkommen werden, hat auf beiden Körperseiten nur zwei Wurzeln $y$ und $z$ ( $x$ ist verschwunden, kann aber auch permanent erhalten bleiben). Die vordere Wurzel $y$ verlässt das Hirn auf dem letzten Schnitt durch die Ohrkapsel, welche also jetzt bis gerade über diese Wurzel nach hinten gewachsen ist. Dieselbe ist, wie erwähnt, noch nicht vom Knorpel des Parachordale umrandet. Die zweite und hintere Hypoglossuswurzel $z$ aber ist jetzt vom Vorderrande

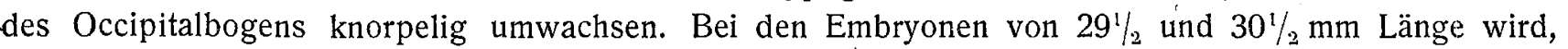
wie erwähnt, der Occipitalbogen gleichfalls schon von der letzten Hypoglossuswurzel durchbohrt.

Der Hinterrand des Occipitalbogens weist eine tiefe Incisur auf - fast zum Foramen geschlossen - für die ventrale Wurzel des 1. Spinalnerven. Ein wirklicher Verschluss findet aber in der Regel bei Acanthias nicht statt. Wohl ist dies nach Braus bei Spinax der Fall.

Das dorsale Basale über welchem die ventrale Wurzel des ersten Spinalnerven in jüngeren Stadien hervortritt und auch das zugehörige ventrale Basale sind als solche nicht mehr erkennbar, da sie in das Ende des Parachordale aufgegangen sind. Von einem Neuralbogen ist hier kaum die Rede; auch später kommt er nicht zur Entfaltung. Die dorsale Wurzel des 1. Spinalnerven liegt mit ihrem Ganglion an der lateralen Fläche des 1. Intercalare. Das Ganglion ist in Rückbildung begriffen und kleiner als die unmittelbar folgenden.

Im Rumpfe verwächst an der Seite der Chorda die dorsale mit der ventralen Basalleiste in kranio-kaudaler Richtung zu einer Knorpelplatte. Bei den Exemplaren von 291/2 und 30 $/ .2 \mathrm{~mm}$ Länge ist diese Verwachsung nur bis zur 2. Wirbelanlage, beim Exemplar von $32^{1 / 2} \mathrm{~mm}$ schon bis zur 8 . Anlage (die in den Schädel aufgenommene als erste gerechnet) vorgeschritten. Hier liegt hinter dem Schädel also eine paarige Knorpelplatte gegen die knorpelige (collagene) Chordascheide. Dieselbe hängt rostralwärts mit dem Schädel zusammen und weist sieben Querleisten auf, von denen jede in der Mitte etwas eingeschnürt ist und einem verschmolzenen oberen und unteren Basale entspricht. Die 7. Querleiste entspricht dem 8. oberen und unteren Basale.

Der $N$. hypoglossus, auf den wir jetzt zurückkommen, zeigt beim Embryo von $301 / 2 \mathrm{~mm}$ Länge eine überraschende und für die Zahl der in den Kopf aufgegangenen Segmente interessante Besonderheit.

Der Nerv hat nämlich auf jeder Körperseite fünf Wurzeln, von denen die letzte durch das Loch im Vorderrande der Occipitalbogens tritt, die übrigen $v, w, x, y$ aber nicht von Knorpel umrandet sind.

Die Überraschung war gross; so viele Wurzeln sollten nicht da sein. Aber die Schnittserie zeigt sie deutlich; man sieht sie aus der Medulla hervortreten. Der Embryo ist übrigens normal. Der Hinterrand des Occipitalbogens hat eine Incisur für die ventrale Wurzel des 1. Spinalnerven. Der obere und untere Bogen der ersten Wirbels sind in den Schädel aufgenommen. Die zugehörige dorsale Wurzel mit noch kräftigem Ganglion kreuzt die Aussenfläche des vordersten von den drei vorhandenen knorpeligen Intercalarien.

Man könnte fragen, ob der Occipitalbogen wohl mit demjenigen der übrigen Embryonen homolog sei; ob er nicht vielleicht ein oder zwei Segmente mehr kaudalwärts aufgetreten wäre. 
Die Vergleichung mit dem Embryo von $28 \mathrm{~mm}$ Länge zeigt aber, dass dies nicht der Fall sein kann. Bei beiden Embryonen ist die Ohrkapsel ungefähr gleichlang. Beim Embryo von $28 \mathrm{~mm}$ Länge ist dieselbe an der rechten Körperseite auf 108 Schnitten, beim andern auf 109 Schnitten sichtbar; an der linken Körperseite verhalten sie sich ähnlich. Beim Embryo von $28 \mathrm{~mm}$ liegt die vorderste $(x)$ der drei Hypoglossuswurzeln hart hinter der Ohrkapsel, beim andern Embryo mit fünf Wurzeln ist dies erst mit der dritten Wurzel der Fall. Die Nerven $x, y, z$ müssen bei beiden Embryonen homolog: sein, weil sie den gleichem Raum zwischen der Ohrkapsel und dem Loch im Occipitalbogen — der Durchtrittsöffnung für die Wurzel $z$ - einnehmen.

Die Wurzeln $v, w, x$ sind rudimentär und ohne zugehöriges Myotom, ihr Austritt aus dem Gehirn ist: auf nur je einem Schnitt vorhanden. Der Austritt der kräftigen Wurzeln $y$ und $z$ umfasst dagegen je 7 Schnitte.'

Die beiden vordersten Wurzeln $v$ und $w$ haben sich ausnahmsweise, aus unbekannten Ursachen, so lang erhalten; sie liegen unter der vorderen Hälfte des breiten Vagusursprunges. Die Wurzel $v$ kreuzt am Parachordale sogar den Vorderrand des Vagus. Sie ziehen als deutliche Nerven unter der Ohrkapsel über das Parachordale, hören an dessen lateralem Rand aber plötzlich auf. Von einer Quetschung durch die Ohrkapsel ist nicht die Rede, da die mit Mesenchym gefüllte Spalte zwischen. derselben und dem Parachordale, auch für einen doppelt dickeren Nerven noch breit genug wäre.

Die fünf Wurzeln weisen hin auf die ehemalige Existenz von fünf metotischen Myotomen. Wir: konnten (Kap. 2) bestätigen, das 6 metotische Somite auftreten, von denen nur das vorderste, dessen vordere Hälfte vom Glossopharyngeus gekreuzt wird, niemals Muskelfasern entwickelt, also niemals. zum Myotom wird. Das zweite metotische Somit, dessen Aussenseite vom Ram. branchialis I Vagi gekreuzt wird, bildet zwar Muskelfasern, dieselben verschwinden aber bald, ohne dass ein zugehöriger Nerv konstatiert werden konnte.

Sollte nun beim Embryo von 30\% mm Länge die Wurzel $v$ dieser Nerv sein, der ausnahmsweise aufgetreten wäre und dessen Lage einem solchen Nerven entspricht? Mir scheint dies die einfachste Erklärung zu sein. Ausnahmen liegen hier jedenfalls vor, wie schon das Vorhandensein der Wurzeln $v$ und $w$ beweist, die beim Austreten aus der Medulla 11 Schnitte von einander entfernt sind, also. nicht als zwei Bündel einer einzigen Wurzel aufgefasst werden können.

Splanchnocranium. Der Kürze wegen wollen wir die Embryonen von $291 / 2,301 / 2$ und $32 \frac{1}{2} \mathrm{~mm}$ Länge resp. als den ersten, zweiten und dritten Embryo bezeichnen. Bei sämtlichen drei sind im. Unterkiefer der, proximale nnd der distale Knorpelherd schon zusammengewachsen. Beim ersten Embryo sind die beiden Herde aber noch durch grösseren Umfang und stärkere Färbung vom Verbin-dungsstück zu unterscheiden.

Im Kiemenapparat fehlen die Hypobranchialia. In jedem Bogen verknorpeln das Cerato- Epiund Pharyngobranchiale ungefähr gleichzeitig. Die nach hinten gerichteten Pharyngobranchialia stützen die Wurzelarterien („Kiemenvenen”) der Aorta. Beim ersten Embryo findet man die Knorpel nur in den drei vordersten Kiemenbogen (im dritten Bogen sind dieselben noch kaum blau) beim zweiten Embryo sieht man sie in den vier vordersten und beim dritten Embryo in sämtlichen fünf Kiemenbogen, mit Ausnahme des 5. Pharyngobranchiale, das noch fehlt. Im dritten Embryo ist ventral am Pharyx schon das Cardiobranchiale aufgetreten, obgleich noch keine knorpeligen Hypobranchialia vorhanden sind.

Die Knorpel werden sämtlich selbständig angelegt. Die Epi- und Ceratobranchialia, mit Ausnahme derjenigen der 5. Bogens, zeigen eine Besonderheit, nämlich ein geräumiges ringförmiges Loch, dessen Rand dem $M$. adductor zur Befestigung dient. Der Ring entsteht, indem der Knorpel das Ende des Muskels hufeisenförmig umwächst, während sich darauf die Enden des Hufeisens verlöten. Der Knorpel wird also nicht etwa secundär durchbohrt. Das Loch wächst später knorpelig zu (ist an den Epibranchialia aber noch im Stadium von $39 \frac{1}{2} \mathrm{~mm}$ Länge offen, sieh Fig. $3 a$ und $3 b$, Taf. XI) und bildet dann die bekannte Mulde zur Befestigung des Muskels.

Am Schultergürtel sind Scapula und Coracoid beim ersten und zweiten Embryo noch getrennt. Beim dritten Embryo sind sie aber an jeder Körperseite zu einem Stück verlötet, das an der ventralen Mittellinie schon im Begriffe steht mit demjenigen der andern Seite zu verschmelzen. Bei diesem Embryo fängt der Knorpel auch in den Basalia der Brustflosse aufzutreten an.

Nach Analogie mit dem Schultergürtel von Pleuracanthus erwartete ich ein selbständiges Knorpelstück am unteren Ende des Coracoids. Dasselbe existiert aber weder an den Total- noch an den Schnittpräparaten. 


\title{
6. Querschnittserie durch einen Embryo von $39^{1 / 2} \mathrm{~mm}$ Länge.
}

\author{
Modell Fig. $3 a$ und $3 b$, Taf. XI, Textfig. 4.
}

Das Skelett dieses Embryos ist weiter entwickelt als bei den Exemplaren von $43 \mathrm{~mm}$ Länge aus Helder, aber weniger weit als bei denjenigen von $40 \mathrm{~mm}$ Länge aus Helgoland; welche oben (Kap. 3) behandelt wurden.

Das akrochordale Polster des Infundibulums ist in der Medianebene reduziert. Aus dem Chordahaken ist es fast verdrängt, indem beide Spangen desselben sich beinahe berühren, die Krümmung also fast $180^{\circ}$ beträgt. Die umgebogene Hakenspange ist sehr verschmächtigt und bildet einen unbedeutenden Anhang. In einer Sagitialschnittserie dieses Stadiums ist derselbe nur auf dem Medianschnitt (von $15 \mu$ Dicke) sichtbar. Man möchte glauben, der Anhang werde bald verschwinden. Doch finde ich ihn in dieser Gestalt noch bei einem Embryo von $80 \mathrm{~mm}$ Länge; ältere wurden nicht geschnitten. Wegen der aufgetretenen Brückenbeuge (SEWERTzOFF) ist die Chorda hinter der Hakenkrümmung etwas aufwärts gerichtet. Sie biegt sich in späteren Stadien stärker hinauf.

Sämtliche Knorpel des Neurocraniums sind mit einander zu einem Ganzen verschmolzen; das Schädeldach ist noch nicht gebildet. Die Nasenkapsel ist noch knorpelfrei, aber am Auge ist der Skleralknorpel aufgetreten. Der unpaare mediane Rostralstab endet noch mit freier Spitze. Dieselbe hat sich noch nicht löffelartig verbreitert wie bei dem etwas weiter entwickelten Embryo, dessen Schädel SEwERTzoff (1899, Fig. 13) abgebildet hat. In prochondralem Zustand, als verdichtetes Mesenchym, ist diese das Vorderhirn von unten her stützende Verbreiterung aber vorhanden.

Hinter der interorbitalen Trabekelplatte sind die Trabekeln noch paarig. Der Schlitz zwischen denselben setzt sich kaudalwärts noch in das sehr verkleinerte Polfenster fort. Der hintere Teil desselben hat sich nämlich als Foramen caroticum abgeschnürt, indem der unpaare mediane Knorpelkern, der bei den Embryonen von $43 \mathrm{~mm}$ Länge aus Helder in der Mitte des Fensters aufgetreten war, sich mit den Seitenwänden desselben verlötet hat. Dorsal werden die Parachordalia von der Begrenzung des Foramen caroticum ausgeschlossen, indem hier die Basis des früheren Polknorpels mit derjenigen der andern Seite zu einer queren Crista verwächst, die mit der unteren Fläche der Parachordalia kontinuierlich ist.

Die Carotis interna ist in diesem Stadium schon mit derjenigen der andern Körperseite verschmolzen, ehe sie von hinten her durch das vom Polfenster abgeschnürte Foramen in den Schädel tritt. Hier spaltet sie sich bald in einen rechten und linken Gabelzweig, der an der Seite der Hypophysis vor-

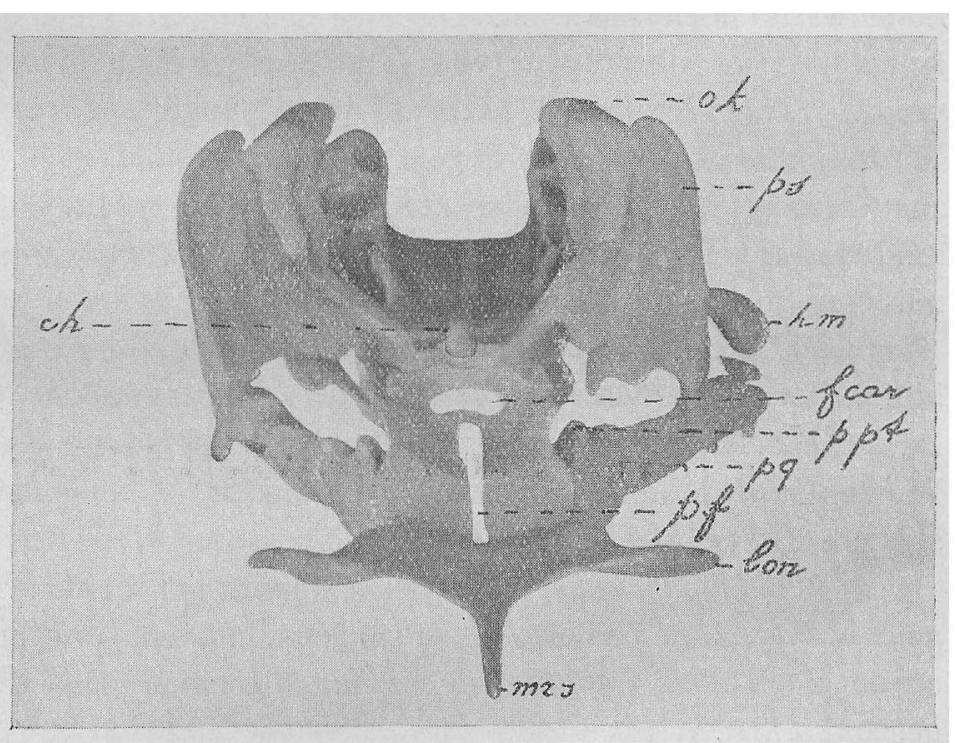

Fig. 4. Vorderansicht des Modelles der Taf. XI, Fig. 3a und 3b. Buchstabenerklärung am Schluss der Arbeit. beizieht, am Vorderrand des Polknorpels lateralwärts tritt und sich weiter rostralwärts wie früher (vgl. Kap. 4) verhält. Der Hypophysengang ist jetzt verschwunden; bei einem wenig jüngeren Embryo (35 mm lang) tritt er vor dem Carotisforamen aus dem Polfenster.

Als neue Erscheinung in dieser Gegend ist die noch enge Queranastomose, die den weiten orbitalen Sinus mit demjenigen der andern. Körperseite verbindet, aufgetreten. Dieselbe zieht über dem Hinterende der Hypophysis an der Vorderfläche der Polknorpel vorbei, ein wenig hinter der Stelle an welcher sich die Carotis interna seitwärts wendet zur Vereinigung mit der Car. spiracularis.

- Der knorpelige Orbitalrahmen ist noch nicht ganz fertig, sondern hat an der vorderen, oberen Ecke eine Lücke, indem sich hier die freien Enden des Pleurosphenoidknorpels und der Lamina orbitonasalis noch nicht berühren. Der Pleurosphenoidknorpel ist eine breite, aber dünne, fast sagittal 
gestellte Platte, welche das vom Orbitalrahmen umgebene Fenster beträchtlich einengt. Seine schmale, stielförmige Basis, die mit dem Ende des Parachordale verlötet ist, trägt am Vorderrand eine tiefe Incisur, durch welche der Oculomotorius in die spätere Orbita tritt. Dieselbe schliesst sich bald zum. Foramen, so dass der Sphenoidknorpel dann Durchtrittsöffnungen für zwei Nerven: Trochlearis und Oculomotorius aufweist.

Die Incisura antotica ist dorsal noch nicht durch Knorpel verschlossen. Ein Streifen verdichteten Mesenchyms (Vorknorpels) ist hier aber schon vorhanden. Am Boden der Incisur ist die Austrittsöffnung des Trigeminus und Facialis noch nicht durch eine Knorpelbrücke von derjenigen des Abducens getrennt.

An der Ohrkapsel fehlt eine mediale Knorpelwand noch fast ganz. Der vom Parachordale ausgehende dreieckige Fortsatz hinter der Eintrittsstelle des N. acusticus ist noch wenig gewachsen. Am vorderen und hinteren Pole sind die frühere Cart. anterolateralis und Cart. posterior einwärts gekrümmt. Vor der Ausmündungsstelle des Ductus endolymphaticus verbindet das vorknorpelige quere: Tectum synoticum beide Kápseln.

Kaudalwärts hat sich die Kapsel so weit verlängert, dass ihr Hinterrand in einer Querebene liegt, die das hintere Loch (für die Wurzel $z$ ) im Occipitalbogen trifft.

Der Chordahaken ist noch ganz knorpelfrei. Hinter dem Polfenster aber dringen Zellen und blaue Grundsubstanz, vom Parachordale ausgehend, in die Seitenwand der collagenen Chordascheide. Etwas weiter kaudalwärts ist dieselbe auf dem Querschnitt schon ringförmig verknorpelt und diese Knorpelhülse setzt sich kontinuierlich in den Rumpf fort. Eine ziemlich dicke innere Schichte der Scheide, auf dem Querschnitt gleichfalls ringförmig, ist dabei noch frei von Zellen und Knorpelgrundsubstanz.

Die Parachordalia sind ausserhalb der Scheide noch in ganzer Länge paarig.

Der Occipitalbogen ist noch nicht mit der Ohrkapsel verwachsen, so dass die Incisura metotica dorsalwärts noch offen ist. Dieselbe lässt jetzt allein den Vagus hindurchtreten. Vorn hat sich nämlich der Glossopharyngeus von derselben getrennt, indem er vom Knorpel der Ohrkapsel umwachsen wurde. Hinten ist die Wurzel $x$-des Hypoglossus verschwunden, während die Wurzel $y$ auch vom Vorderrande des Occipitalbogens umgeben ist. Derselbe ist also an der Basis zweimal durchlöchert: zur Öffnung für die Wurzel $z$ ist noch eine zweite, für die Wurzel $y$, hinzugekommen. Der Hinterrand des Bogens hat die ventrale Wurzel der 1. Spinalnerven nicht umwachsen und bildet für dieselbe nur eine seichte Incisur.

Die Accessoriuswarzel des Vagus ist ein unscheinbares Bündel, das nur noch auf 8 Schnitten hinter der Stelle wo der Vagus am Vorderrande des Occipitalbogens vorüberstreicht, zu sehen ist. Dasselbe erreicht die Region der letzten Hypoglossuswurzel nicht mehr und würde unter den übrigen Wurzelbündeln keine Erwähnung verdienen, wenn es sich in früheren Stadien nicht durch seine besondere Stärke und seine Beziehungen zu den Hypoglossusganglien unterschieden hätte.

Der Hypoglossus hat, wie erwähnt, auf beiden .Körperseiten nur zwei Wurzeln $y$ und $z$. Sie sind kräftig. Ihre beiden Austrittslöcher sind, wie erwähnt, entstanden indem die rostralwärts vorwachsende Basis des Occipitalbogens für dieselben besondere Öffnungen von der Incisura metotica abgeschnürt hat.

An der Wirbelsäule ist die kontinuierliche Knorpelplatte, welche, vom Schädel ausgehend, der Seitenfläche der knorpeligen Chordascheide anlag, jetzt in Gliederung begriffen. Es scheint, dass dieselbe durch das Längen- und Dickenwachstum der Chorda samt deren Scheide verursacht wird. Von der früheren Knorpelplatte existiert nur noch der ventrale Teil, der die ersten 8 unteren Basalia umfasst. Die folgenden unteren Basalia (bis zum 11. wurde geschnitten) sitzen als isolierte Knorpelinseln der Chordascheide an.

Die trapezförmigen Neuralbogen (oberen Basalia) sind schon vom 4. an isoliert (der 1. in den Schädel aufgenommene nicht mitgerechnet). Auch der 1., 2. und 3. Bogen berühren einander an der Basis nicht mehr, hängen aber ventralwärts mit der unteren Basalplatte noch knorpelig zusammen.

Von den 5 Intercalarien alternieren die 4 hintersten mit den 4 vordersten Neuralbogen. Das 1. Intercalare folgt scheinbar direkt auf dem Occipitalbogen, da die Anlage des 1. Wirbels in das Hinterende des Parachordale aufgegangen und der zugehörige Neuralbogen nicht zur Entwicklung gekommen ist. 
Bei einem Embryo von $80 \mathrm{~mm}$ Länge, dem ältesten, den ich in Querschnitte zerlegt habe, existiert auch der vordere Teil des unteren Basalstreifens nicht mehr als ein kontinuierliches Stück, sondern ist in seine Glieder auseinandergefallen. Doch ist der 1., 2. und 3., ein wenig auch der 4. Neuralbogen je mit dem zugehörigen ventralen Basale in Zusammenhang geblieben. Die Intercalaria sind im Rumpfe vollzählig vorhanden und werden schon von den dorsalen Nervenwurzeln durchbohrt, die früher oben an ihrem Vorderrande vorbeizogen.

Der dorsale Verschluss des Spinalkanales bleibt noch lange Zeit aus. Noch bei Embryonen vom $105 \mathrm{~mm}$ Länge (Methylenblaupräparate) ist derselbe dorsal weit offen. Eine unpaare Reihe von Deckstücken, die sonst ziemlich allgemein bei Selachiern und Holocephalen angetroffen wird, kommt bei. Acanthias nicht vor. Beim geslechtsreifen Tier findet man den Kanal oben verschlossen, indem je ein Intercalare mit demjenigen der andern Körperseite zu einem unpaaren Knorpelstück verwachsen ist. Diese Stücke schliessen im Vorderrumpf am Dache des Spinalkanals unmittelbar an einander und fasen an der Seitenfläche desselben die spitzen Gipfel der Bogen zwischen sich ein, welche in der Region vor dem Schultergürtel ziemlich weit von der dorsalen Medianlinie entfernt bleiben.

Splanchnocranium. Lippen- und Spritzlochknorpel, Kiemenstrahlen und Extrabranchialia zeigen: noch keine Chondrifizierung. Sogar die Hypobranchialia, und Basibranchialia mit Ausnahme des Cardiobranchiale, sind noch nicht verknorpeit.

Die 5 Epi- und Ceratobranchialia sind sämtlich vorhanden, aber nur 4 Pharyngobranchialia; das 5. fehlt noch.

Ein knorpeliger Zusammenhang der Unterenden der Ceratobranchialia (GiBian, 1912) ist auf meinen Präparaten, auch in jüngeren Stadien, nicht vorhanden.

Die beiden Stücke des 5 . Kiemenbogens (Epi- und Ceratobranchiale) werden von Anfang an solid angelegt. Die 4 vordersten Epibranchialia sind noch durchlöchert. In den Ceratobranchialia hat sich das Loch aber verschlossen, mit Ausnahme des 1. Ceratobranchiale der rechten Körperseite, das noch einen kleinen Rest der Öffnung aufweist.

Ich finde das Loch im Epi- und Ceratobranchiale der 4 vordersten Kiemenbogen auch bei Embryonen von Scyllium canicula, Pristiurus melanostomus und Torpedo ocellata, nicht aber bei solchen von Heptanchus cinereus, von dem mir aber nur zwei Stadien resp. von 63 und $95 \mathrm{~mm}$ Länge zur Verfügungs stehen. Die Embryonen sind aber zu weit entwickelt, um auf das Fehlen der Löcher, auch in jüngeren Stadien schliessen zu können.

Bei Embryonen sind die Löcher meines Wissens von früheren Autoren nicht wahrgenommen. Interessant ist nun, dass diese primitiven Bildungen bei zwei erwachsenen Formen beobachtet worden sind. HASWELL (1885) fand sie nämlich bei Crossorhinus (Orectolobus) barbatus in den 4 vordersten Epibranchialia (die entsprechenden Ceratobranchialia hatten nur je eine tiefe Mulde für den $M$. adductor). Bei Pristiophorus cirratus, von dessen Kiemenskelett er auch eine Abbildung gibt, fand er die Löcher sogar an sämtlichen vier vordersten Epi- und Ceratobranchialia.

Crossorhinus, ein Galeoide, weist am Rostrum seines eigentümlich spezialisierten Schädels und auch an der Wirbelsäule primitive Merkmale auf.

Pristiophorus, ein Squaloide, mit sehr spezialisierter Schnauze hat wegen der Durchlöcherung, auch der Ceratobranchialia, einen noch primitiveren Kiemenkorb als Crossorhinus. Sein nächster Verwandte, Pliotrema, zeigt durch den Besitz von 6 Kiemenspalten ein andres primitives Verhalten.

Nachdem RegaN (1908) diese Form aufgefunden hat, kann man nicht mehr wie früher im Gegensatz mit den Notidanoiden die übrigen Haifische als pentanche bezeichnen, um so weniger da SMITH (1912) einen neuen Notidanoiden: Pentanchus profundicolus, mit nur 5 Kiemenspalten hinter dem Spritzloch entdeckt hat. 


\section{RÜCKBLICK}

\section{a. Die Wirbelsäule}

Das erste Stadium der knorpeligen Wirbelsäule bei Acanthias und Scyllium ist an jeder Körperseite ein oberer und ein unterer Knorpelstreifen (Basalstreifen) an der Seitenfläche der Chorda. Jeder Streifen hängt kontinuierlich mit" dem Parachordale des Schädels zusammen und zeigt die Anlagen der oberen resp. unteren Basalia (Bogen) als kleine Verdickungen. Die collagene (faserige) Chordascheide ist noch frei von Zellen. Die Anlagen des ersten oberen und unteren Bogens werden bei Acanthias jetzt bleibend dem Schädel einverleibt.

Rasch folgt nun das zweite Stadium: Die beiden Streifen verwachsen bei Acanthias in kraniokaudaler Richtung zu einer dünnen, paarigen Platte. Dieselbe liegt der Seitenfläche der collagenen Chordascheide an, die inzwischen zellig und knorpelig geworden ist. Die Platte hängt kontinuierlich mit dem Parachordale zusammen und reicht kaudalwärts wenigstens bis zur 8. Wirbelanlage. Die wenigen ersten Intercalaria treten als selbständige Knorpel in kranio-kaudaler Richtung auf.

Bald fängt dạs dritte Stadium an, in welchem sich die Bogen von einander und vom Schädel isolieren. Der 1. 2. und 3. Neuralbogen bleiben aber je mit dem zugehörigen unteren "Bogen” verschmolzen.

Bei Acanthias kommt es also unmittelbar hinter dem Kopf zu einem abortiven Versuch eine dem Parachordale des Schädels ähnliche kontinuierliche Knorpelplatte zu bilden.

Bei den Rochen und Holocephalen dagegen wird dieser Versuch weiter ausgebildet und führt zum Knorpelrohr, das den vorderen Abschnitt des Rückenmarkes und den entsprechenden Teil der Chorda umschliesst. Bei den Rochen unterstützt dieses Rohr den die dorsale Mittellinie erreichenden Schultergürtel, bei den Holocephalen den Rückenstachel. Bei Acanthias strebt der Schultergürtel mit dem Suprascapulare dorsalwärts hinauf, ohne die Mittellinie zu erreichen.

Schon GöTTE (1878) ist es aufgefallen, dass die Lage der Nervenwurzeln in bezug auf die Bogen und Intercalarien bei Embryonen von Acanthias eine andre ist als bei solchen von Scyllium.

Bei Acanthiasembryonen von $50 \mathrm{~mm}$ Länge durchbohrt die ventrale Wurzel eines Spinalnerven einen Bogen, während die dorsale Wurzel oben am Vorderrande des folgenden Intercalare vorbeizieht; dasselbe ist also nicht zwischen beiden Wurzeln eingeschcben; sein Vorderrand umwächst die dorsale Wurzel aber später.

Bei Scylliumembryonen dagegen tritt zwischen den beiden Wurzeln eines Spinalnerven ein Intercalare auf an dessen Hinterrand die dorsale Wurzel vorbeizieht. Die ventrale Wurzel tritt am Vorderrande des Intercalare hinter dem vorhergehenden Bogen aus (vgl. die Abbildung von Acanthias bei Sewertzoff, Fig. 22; von Scyllium bei GoOdrich, Fig. 17).

Es ist ein eingreifender Unterschied, ob ein Intercalare die Wurzeln eines Nerven trennt oder nicht. Es liegen hier zwei verschiedene Typen der Wirbelbildung vor ${ }^{1}$ ).

Auch die Form der Knorpel ist in beiden Typen verschieden. Bei Acanthias sind Bogen und Intercalaria dreieckig; die Basis des Bogens liegt unten, diejenige des Intercalare oben. Bogen und Intercalaria sind so zu sagen in einander gekeilt, so dass sie sich mit schief gestellten Rändern berühren. Bei Scyllium sind Bogen und Intercalaria in dorsoventraler Richtung länglich ausgezogen, so dass ihre Berührungsränder parallel und senkrecht (sagittal) verlaufen.

Diese beiden Typen, die wir den spinaciden und den scylliden Typus nennen werden, haben für die Selachier allgemeinere Bedeutung. Man findet sie auch bei den erwachsenen Formen, ich darf wohl sagen sämtlicher Genera. Bei denselben kann die Form der Knorpel durch den Druck der Nachbarteile mehr oder weniger modifiziert sein. Der charakteristische Unterschied bleibt aber die Lage

1) Denkt man sich bei Scyllium die beiden Knorpel (der Bogen und das folgende Intercalare) zwischen welchen die ventrale Nervenwurzel austritt oberhalb und unterhalb derselben mit einander verwachsen, so erhält man das Homologon des durchbohrten Neuralbogens von Acanthias. Ein Homologon des Intercalare von Acanthias kommt dann am Wirbel von Scyllium nicht vor.

Eine Beschreibung der Beobachtungen zu Gunsten dieser Áuffassung (nach SCHNEIDER) würde mich hier viel zu weit führen. In einer andern Arbeit beabsichtige ich näher darauf einzugehen. 
des Intercalare, entweder zwischen beiden Wurzeln eines Spinalnerven oder hinter denselben, wenngleich in beiden Fällen das Intercalare nachträglich von der dorsalen Wurzel durchbohrt sein kann.

Bei HASSE (1882-1885) findet man von den meisten Genera Teile der Wirbelsäule in seitlicher. Ansicht abgebildet. Wenn wir mit TATE Regan (1906) die Familien der Haifische nach äusseren und inneren Merkmalen in drei Gruppen: Notidanoidei, Squaloidei und Galeoidei vereinigen ${ }^{1}$ ), so stellt sich heraus, dass die Galeoidei (HASsE, Taf. 25 bis 40) den Scylidentypus, die Notidanoidei und Squaloidei, aber auch die Rochen und Holocephalen den Spinacidentypus der Wirbelsäule besitzen ${ }^{2}$ ).

HASSE bringt Cestracion (Taf. 24, Fig. 1 und 3; ausführlicher bei DANIEL, 1915, Plate 5) wegen der asterospondylen Natur seiner Wirbelkörper in die Nähe der Scylliden. Die Bogen zeigen aber deutlich den Spinacidentypus. Da dieselben viel früher auftreten als die gewebliche Differenzierung der Körper, so geben sie diesen gegenüber ein mehr primäres Merkmal zur Klassifizierug an die Hand. Deshalb gehört Cestracion (Heterondotus) nicht in die Gruppe der Galeoiden, sondern in diejenige der Squaloiden zu welcher er auch von REGAN aus andern Gründen gestellt wird.

Bei Acanthias ist das erste, dem Schädel folgende Element der Wirbelsäule das erste Intercalare (welches von der dorsalen Wurzel des 1. Spinalnerven durchbohrt wird und zum Wirbel gehört, dessen Basalia in die Schädelbasis aufgenommen sind) bei Scyllium dagegen der erste Bogen.

Auch diese Differenz gilt wohl allgemeiner zwischen Squaloiden (vgl. FüRBRINGER, Taf. I, Spinax, Centrophorus, Cestracion, bei denen der erste Spinalnerv aber unrichtig mit $z$ bezeichnet ist) und Galeoiden ${ }^{3}$ ).

Auf den ersten Blick muss man glauben, dass hier ein wesentlicher Unterschied in der Schädelgrenze zwischen Squaloiden und Galeoiden bestehe. Derselbe wird aber sofort hinfällig wenn die Intercalaria von Acanthias nicht bei Scyllium auftreten (vgl. die Anm. p. 290). Auch bei Scyllium müssen die Basalia des 1. Wirbels - wenigstens phylogenetisch - in die Schädelbasis aufgenommen sein, denn der Körper des 1. freien Wirbels gehört mit dem zügehörigen 1. Intercalare und dem 1. Bogen (vgl. Goodrich, Fig. 17) zum Segment der 2. Spinalnerven.

Auch bei Laemargus (WHITE, 1892) ist der Körper des ersten Wirbels mit der Schädelbasis verschmolzen und dies ist wohl allgemeiner bei Selachiern der Fall. Nach meiner Auffassung (sieh unten) muss dieser Wirbel mit dem vielgesuchten Proatlas bei Amnioten homolog sein. Interessant ist dass sein kurzer Körper bei Heterodontus francisci (DANIEL, 1915) nicht in die Schädelbasis aufgenommen ist.

\section{b. Der Occipitalbogen}

Dieser Bogen verdient unsere besondere Aufmerksamkeit, da er in jungen Stadien des Kopfskeletts sämtlicher Gnathostomen erscheint und neural das morphologische Hinterende des Schädels angibt.

Bei den Fischen sind ihm kaudalwärts vielfach Wirbelelemente angeschlossen, die zum Teil oder sämtlich mit dem Schädel verschmelzen, so dass die Bestimmung der hinteren Grenze desselben ohne Kenntnis der Entwicklung öfters nicht möglich wird. Dies ist z. B. bei Heptanchus, beim Stör und vielen andern Fischen der Fall. Der Versuch von FüRBRINGER in seiner umfang- und inhaltreichen Arbeit (1897) diese Grenze auf rein anatomischem Wege zu bestimmen, mag manchmal gelungen sein, in vielen Fällen hat sich derselbe aber als irrtümlich herausgestellt.

1) $\mathrm{Zu}$ den Squaloidei gehören, abgesehen von ausgestorbenen Formen, die Familien der Cestraciontidae, Spinacidae, Pristiophoridae und Squatinidae. Nach Abzug der Notidanoidei gehören die übrigen Haifische zur Gruppe der Galeoidei, deren Schädel, mit Ausnahme einiger Orectolobidae, durch das dreistrahlige Rostrum gekennzeichnet ist.

2) Auf kleine Modificationen des Typus - z. B. dass auch im Scyllidentypus die ventrale Nervenwurzel bisweilen secundär von Knorpel umrandet wird - kann hier nicht eingegangen werden. Für die Abbildungen der Wirbel von Lamna muss ich aber eine Ausnahme machen. Das ausgebildete Tier (HASSE, Taf. 28, Fig. 2) zeigt deutlich den Scyllidentypus, ein angeblicher Embryo aber (ibidem Fig. 4) ebenso deutlich den Spinacidentypus. Man muss sich fragen ob dieser Embryo wohl richtig bestimmt ist.

3) Ein weiterer Unterschied hat Bezug auf das Verhalten der Chorda im Schädel. Dieselbe erhält sich bei den meisten Squaloidei als ein kontinuierlicher Faden, rostralwärts bis an die Sella turcica. Dies fand man (vgl. hauptsächlich Gegenbaur, 1872) bei Acanthias, Centrophorus, Laemargus, Echinorhinus, Cestracion und Squatina. Dagegen scheint Scymnus eine Ausnahme zu machen. Soviel ich weiss, hat man bei keinem ausgebildeten Galeoiden einen solchen kontinuierlichen Faden gefunden. Vielleicht existiert er in der Fam. der Orectolobidae. 
Die Frage nach der Homologie des Occipitalbogens bei den verschiedenen Gruppen der Wirbeltiere kann hier nur sehr flüchtig gestreift werden; eine eingehende Behandlung würde eine Abhandlung für sich bilden.

Dass der Bogen bei Selachiern streng homolog ist, kann, wie ich glaube, nicht mehr mit Grund bezweifelt werden. Bei Embryonen von sehr verschiedenen Gruppen wie Acanthias, Scyllium und Torpedo hat er eine zeitlang die so charakteristische Form eines Dreiecks, das sich vom Ende des Parachordale erhebt und an der Basis nur von der letzten Hypoglossuswurzel durchbohrt wird. Es ist zu erwarten, dass er in dieser Gestalt auch bei Embryonen von Notidanoiden vorkommt; dann wird es möglich sein auch bei dieser Gruppe die letzte Hypoglossuswurzel $z$ zu bestimmen.

Wahrscheinlich hat der Bogen nicht nur bei Scyllium und Pristiurus, sondern auch bei den übrigen Galeoiden die gleiche Form. Dann ist derselbe aber bei sämtlichen Selachiern nicht wie die Neuralbogen der Wirbelsäule nach zwei verschiedenen Typen, sondern nach einem einzigen Typus gebaut. Dies ist auffallend, aber der Schädel wird ontogenetisch und auch wohl phylogenetisch früher angelegt als die Wirbelsäule und der Scyllidentypus derselben muss in frühen geologischen Perioden aufgetreten sein, nachdem der Occipitalbogen schon gebildet war.

Bald nachdem der Occipitalbogen angefangen hat zu verknorpeln, umwächst sein Vorderrand die Hypoglossuswurzel $z$. Durch die dorsalwärts offene Incisura metotica zwischen Bogen und Ohrkapsel treten die übrigen Wurzeln und der Vagus (anfangs auch der Glossopharyngeus) hervor. Die Basis des Bogens wächst rostralwärts weiter und umgibt nacheinander die übrigen Wurzeln, sofern sie nicht vorher abortiert sind. Nachdem so die Canales hypoglossi von der Incisura metotica isoliert sind, schliesst sich dieselbe zum Foramen, indem der Gipfel des Occipitalbogens mit der medialen Fläche des Hinterendes der Ohrkapsel verwächst.

Die Säugetiere verhalten sich ähnlich, indem auch bei ihnen die Canales hypoglossi durch den Vorderrand des Occipitalbogens von der Incisura metotica, die zum Foramen jugulare wird, abgeschnürt werden, vgl. NOORDENBOS (1905).

Wenn nun bei Fischen sich Wirbelelemente dem Schädel anschliessen, so können die zugehörigen Spinalnerven nicht vom Vorderrande, sondern nur vom Hinterrande des Occipitalbogens her dem Kranium zugefügt werden.

Es wirkt verwirrend, wenn einige Autoren die sekundär mehr oder weniger dem Schädel einverleibten Gebilde auch Occipitalbogen nennen. Man kann sie passender als Occipito-spinalbogen bezeichnen.

Bei Selachiern (Acanthias und Scyllidae) liegt der Bogen an dem Septum welches das 5. metotische Myotom (das 10. Kopfsegment) nach hinten begrenzt. Vier Hypoglossuswurzeln sind schon von früheren Beobachtern konstatiert. Nach der Verknorpelung des Bogens sind nur noch die letzten zwei oder drei Wurzeln vorhanden. In einem Ausnahmefall waren aber fünf Wurzeln zu gleicher Zeit anwesend, die wahrscheinlich den 5 metotischen Myotomen, von denen die vordersten schon verschwunden waren, entsprechen.

Ich halte dafür, dass der Occipitalbogen bei sämtlichen Wirbeltieren homolog ist, d. h. dass derselbe bei sämtlichen die hintere Grenze des 10. Kopfsegmentes angibt. Endgültig beweisen lässt sich diese Auffassung nicht, doch sehe ich auch nichts was ihr widerspräche.

Meines Wissens sind bei Wirbeltierembryonen nirgends mehr Hypoglossuswurzeln als bei Selachiern nachgewiesen. Auch werden nirgends mehr als 6 Occipitalsomite angelegt.

Bei Vögeln fand Sonies (1907) dass das Hinterende des Parachordale anfangs eine Gliederung in zwei Wirbelkörper erkennen lässt. Dem vorderen derselben entspricht der Occipitalbogen, der hintere erhält einen kleineren Bogen, den SONIES als einen zweiten Occipitalbogen auffasst. Ich möchte lieber annehmen, dass sich hier, wie bei Acanthias ein Wirbelkörper dem Schädel angeschlossen hat. Der Occipitalbogen ist bei Vogelembryonen durchans selachierähnlich (vgl. Sonies 1.c. Fig. 9 bis 12).

Auch bei Reptilien scheint sich ein Wirbelkörper dem Schädel anzuschliessen. ScHauinsLand (1905, Fig. 309) fand nämlich bei einem Embryo von Sphenodon den mutmasslichen Körper eines ehemals noch vor dem Atlas gelegenen Wirbels und ist geneigt (l. c. p. 541) denselben für den Körper eines Proatlas $\mathrm{zu}$ halten.

Bei Säugetieren dagegen findet nach BARGE (1917) kein Anschluss eines Wirbelkörpers statt. 
Die hintere Schädelgrenze (beim Schaf) sei eine intersegmentale und nicht eine intrasegmentale wie die Grenze zwischen zwei Wirbelkörpern. Die rostrale Hälfte des 1. spinalen Sklerotoms werde nicht in den Schädel aufgenommen.

Der Occipitalbogen der Amphibien wird vielfach zu einem viel weiter rostralwärts liegenden Kopfsegment gerechnet als bei den Selachiern, weil die Zahl der Hypoglossuswurzeln bei Amphibien sehr reduziert ist, der ganze Nerv sogar unterdrückt sein kann. Aber dasselbe kommt bei den Rochen vor, bei denen doch eine gute Zahl Kopfmyotome konstatiert werden konnte, zwar eine noch viel grössere Zahl hineinphantasiert worden ist.

Bei Ceratodus werden hinter dem Occipitalbogen jederseits zwei Occipitospinalbogen dem Schädel einverleibt. Der mittlere dieser drei Gebilde ist mehr oder weniger rudimentär.

Vor dem Occipitalbogen werden nach KraweTz (1911) und Greil (1913) fünf Myotome angelegt; die beiden ersten verschwinden später. Dies stimmt also mit den Verhältnissen bei Selachiern überein. In einem Falle fand KRAWETZ 6 Myotome vor dem ersten oberen Bogen und glaubte dieser sei der mittlere der drei Bogen des ausgebildeten Tieres, der erste (der eigentliche Occipitalbogen) komme nicht zur Anlage. Ob diese Erklärung richtig sei, lasse ich dahingestellt. Bei Selachiern wurden, wie wir sahen, 6 Occipitalsomite konstatiert, von denen das vorderste (dessen vordere Hälfte vom N. glossopharyngeus gekreuzt wird) aber niemals Muskelfasern hervorbringt.

Die Accessoriuswurzel des Vagus ist um die Zeit der Schädelanlage in der Region der Hypoglossuswurzeln kräłtig entwickelt (vgl. GreIL, Taf. 53, Fig. 2).

Eine sehr primitive Erscheinung bei Ceratodus ist das öfters Erhaltenbleiben einer dorsalen Hypoglossuswurzel.

Bei Embryonen von Lepidosteus kommen nach SchreInER (1902) 5 Occipitalmyotome [ $V, W, X, Y, Z]$ vor, das vorderste derselben bildet aber keine Muskelfasern, ist also weiter degeneriert als bei Selachiern und eigentlich kein Myotom mehr. Bei Amia fand SchreIner nur 4 dieser Myotome [ $W, X, Y, Z]$. Die Accessoriuswurzel des Vagus ist um die Zeit der Schädelanlage, wie bei Ceratodus so auch bei Lepidosteus, kräftig entwickelt (vgl. VEIT, Taf. A, Fig. 5) und reicht bis zum ersten Occipitospinalnerv kaudalwärts.

Unter den Fischen ist die Entwicklung des Hinterkopfes speziell bei Acipenser (SEWERTzOFF, 1895) und Amia (Allis 1897; Schreiner, 1902; PeHrson, 1922) interessant, weil der Occipitalbogen bei diesen Formen selbständig hinter dem kaudalwärts wachsenden Parachordale auftritt. Anfangs durch eine knorpelfreie Strecke vom Parachordale getrennt, verlötet er sich erst nachträglich mit demselben.

Dies scheint auch bei Ceratodus der Fall zu sein, doch ist es mir aus den Beschreibungen nicht ganz klar geworden. Lepidosteus ist in dieser Hinsicht, wie überhaupt in der Entwicklung des Parachordale viel mehr selachierähnlich (vgl. den zweifach durchbohrten Occipitalbogen bei VeIT, 1911, Fig. 11 und 13). Die Verhältnisse bei Acipenser und Amia lassen an Zustände bei Petromyzon anknüpfen.

Bei Petromyzon marinus und $P$. fluviatilis unterscheidet sich der erste Wirbelbogen durch seine besondere Grösse und auch dadurch, dass er von einem ventralen und einem dorsalen Nerven durchbohrt wird. Rostral von diesem Bogen werden keine knorpeligen Wirbelelemente mehr angelegt. Die Lücke zwischen demselben und der Ohrkapsel wird durch Membran verschlossen. Bei Petromyzon marinus sah FüRBRINGER (1897) dass, abgesehen vom Glossopharyngeus und Vagus, 2 ventrale und die entsprechenden 2 dorsalen Nerven die Verschlussmembran durchsetzen. Er verneinte aber, dass dieselben mit dem Hypoglossus der Amnioten verglichen werden könnten: 1) weil die beiden ventralen Nerven bei Petromyzon das Hinterende des Kiemenkorbes nicht umkreisen um sich an der Versorgung der hypobranchialen, spinalen Muskulatur zu betätigen und 2) weil er es für ausgeschlossen hielt, dass hier eine grössere Reihe von zurückgebildeten Occipitalmyotomen bestanden habe.

Was nun den ersten Einwand betrifft, so glaube ich nicht, dass man demselben viel Wert beimessen kann. Aus den Gliedmassen der Wirbeltiere können sich ja Muskeln und Nerven frei machen und es ist nicht einzusehen, dass Ähnliches bei der spinalen hypobranchialen Muskulatur nicht stattfinden sollte, wenn der Hypoglossus sich überhaupt bei Stammformen der Cyclostomen an dieser Versorgung beteiligt hat, was nicht der Fall zu sein braucht.

Der zweite Einwand wurde noch in demselben Jahre hinfällig als NraL (1897) bei Ammocoetes 
von $5 \mathrm{~cm}$ Länge fand, dass die 2 vordersten Occipitalnerven dem 4. und 5 . Occipitalmyotom entsprechen. Er glaubt, dass sie auch das 1. bis 3. Occipitalmyotom versorgen. KolTzoff (1902) sagt in seiner belangreichen Abhandlung, dass er bei jüngeren Exemplaren noch einen besonders starken Nerven für das 3. metotische Myotom fand, der seiner Meinung nach auch die Reste der beiden vorhergehenden Myotome innerviert. Er kommt deshalb zum Schluss, dass auf die drei vordersten ventralen Wurzeln des Ammocötes wenigstens fünf metotische Myotome kommen.

Wenn wir nun bei Petromyzon den grossen ersten Wirbelbogen als Occipitalbogen ansehen und den ihn durchbohrenden ventralen Nerv als die Wurzel $z$ des Hypoglossus, so muss derselbe nach Analogie mit den Selachiern der Nerv des 6. metotischen Somites sein. Dies stimmt ganz gut mit den ontogenetischen Befunden überein.

Dass der Bogen isoliert eine Strecke hinter dem Parachordale liegt, hat er mit dem Occipitalbogen von Acipenser und Amia in frühen Stadien gemein.

Bei dieser Auffassung hat der Hypoglossus von Petromyzon marinus drei ventrale Wurzeln, von denen die vorderste ein Komplex von mehreren zu sein scheint. Weiter zeigt der Nerv ein primitives Verhalten durch den Besitz von drei dorsalen Nerven, also noch zwei mehr als bei Ceratodus angetroffen werden. Der hintere derselben durchbohrt den Occipitalbogen.

Die Erklärung, weshalb der Occipitalbogen der Kranioten zu besonderer Entfaltung veranlasst wurde, muss der Zukunft überlassen werden. Die bessere Befestigung der Ohrkapsel, zu welcher derselbe später offenbar belangreich beiträgt, kann wohl nicht als primäre Ursache betrachtet werden.

\section{Zusammenfassung.}

1. Aus dem soliden Zellstrang, der nach der Verödung seines früheren Lumens die Wände der beiderseitigen Höhlen des 1. Kopfsomites (Prämandibularhöhlen) verbindet, entsteht am Chordaende: das unpaare akrochordale Infundibularpolster. Dasselbe weist im Gegensatz mit den Verhältnissen bei Vogelembryonen keine Knorpelbildung auf. Längs des ventralen Chordarandes wächst das Polster kaudalwärts weiter, bis es den Vorderrand des Parachordale erreicht hat.

2. In einem seitlichen Flügel des erwähnten Zellstranges entstehen die Cart. antotica und supraorbitalis, die bald zum Pleurosphenoidknorpel (Alisphenoidknorpel, SEWERTZOFF) verschmelzen.

3. Die ersten 10 Somite gehören zum Kopfe der Selachier. Früher habe ich eines derselben übersehen, so dass ich glaubte es gäbe derén nur 9.

4. Das aus dem 11. Somite gebildete Myotom wird von der ventralen Wurzel des 1. Spinalnerven versorgt. Bei Acanthias hat dieser Nerv, sobald die hintere Grenze des Schädels kenntlich geworden ist, noch ein deutliches Ganglion. Bei Scyllium ist dasselbe dann aber dem Verschwinden nahe.

5. Der dem 1. Spinalnerven beizurechnende 1. Wirbelkörper verschmilzt bei Acanthias (und wohl mit wenig Ausnahmen allgemein bei Selachiern) frühzeitig mit der Schädelbasis. Wahrscheinlich. ist er mit dem Körper des Proatlas der Reptilien und Vögel homolog.

6. Das Parachordale setzt sich an jeder Körperseite bald kontinuierlich in den Rumpf fort in Gestalt eines dorsalen und ventralen Knorpelstreifens (Basalstreifen), welche der Seitenfläche der Chorda direkt anliegen. Durch die Maschen der Elastica dringen nicht nur Zellen, sondern dringt auch reichlich Knorpelgrundsubstanz in die collagene Chordascheide.

7. Die Basalstreifen zerfallen später in die einzelnen Basalia, welche die Wirbelkörper bilden. Auf jedem derselben kommen ein Paar dorsaler und ein Paar ventraler, im ganzen also vier Basalia.

8. Die Neuralbogen der Selachier sind nach zwei verschiedenen Typen, dem spinaciden und dem scylliden Typus gebaut. Der Scyllidentypus kommt nur den Galeoiden zu. Der Spinacidentypus wird bei den übrigen Selachiern (Notidanoiden, Squaloiden, Batoiden), auch bei den Holocephalen angetroffen.

9. Der Schädel der Squaloiden unterscheidet sich von demjenigen der Galeoiden nicht nur durch die Gestalt des Rostrums, sondern auch durch die Erhaltung der Chorda (mit wenig Ausnahmen: Scymnus?). Dieselbe durchzieht als ein kontinuierlicher Faden die ganze Länge der morphologischen Schädelbasis; sie reicht nämlich bis zur Sattelgrube.

10. Am vorderen Ende des Parachordale bildet sich bei Acanthias ein selbständiger Polknorpel, der die Verbindung der Trabecula mit dem Parachordale vermittelt. 
11. Die Basis der Ohrkapsel (Lamina basiotica) ist ein Auswuchs des Parachordale zwischen dem Acustico-facialis und dem Glossopharyngeus. Ausserdem treten noch zwei selbständige Knorpelherde auf, der eine an vorderen, der andre am hinteren Pole der Kapsel. Der Herd am vorderen Pole bildet bald eine Schale an der Aussenseite des Can. semicircularis lateralis.

12. Die Teile des Kiefer- und Zungenbeinbogens, sowie der Kiemenbogen treten sämtlich als selbständige Knorpel auf. Der Unterkiefer von Acanthias chondrifiziert von zwei Knorpelherden aus. Bei Embryonen von Selachiern (auch von Notidanoiden?) sind, mit Ausnahme des letzten Kiemenbogens, das Epi- und Ceratobranchiale kurz nach dem Auftreten durchlöchert.

13. Die Flossenträger (Pinnifera) entstehen' auch im Spinacidentypus unabhängig vom Achsenskelett, mit dem sie erst nachträglich in Verbindung kommen.

14. Im Schultergürtel treten Coracoid und Scapula als selbständige Knorpelherde auf. 


\section{LITERATURVERZEICHNIS}

Allis, E. PhelPS. The cranial Muscles and first spinal Nerves of Amia calva. Journal of Morphology, Vol. $12,1897$. BARge, J. A. J. Die Entwicklung der Cranio-Vertebralgrenze beim Schaf. Anatomische Hefte, I. Abt. Bd. $55,1917$.

BRAus, H. Beiträge zur Entwicklung der Muskulatur und des peripheren Nervensystems der Selachier. MorphologischesJahrbuch, Bd. 27, 1899.

DANIEL, J: F. The Anatomy of Heterodontus francisci. II The Endoskeleton. Journal of Morphology, Vol. 26, 1915.

DoHRN, A. Studien zur Urgeschichte der Wirbelthierkörpers $N^{2}$. 18. Die Occipitalsomite. Mittheilungen aus der Zool Station zu Neapel, Bd. 15, 1901.

FürbRINGER, Max. Ueber die spino-occipitalen Nerven der Selachier und Holocephalen und ihre vergleichende Morphologie. Festschrift für Gegenbaur, 1897.

Gegenbaur, C. Das Kopfskelet der Selachier, ein Beitrag zur Erkenntniss der Genese des Kopfskeletes der Wirbelthiere Leipzig, 1872.

GiBian, Annie. Beiträge zur Kenntnis des Hyobranchialskeletes der Haie. Morph. Jahrbuch, Bd. $45,1912$.

Goodrich, E. S. On the Development of the Segments of the Head in Scyllium. Quarterly Journ. of Micr. Science, Vol. 63, 1918.

GötTE, A. Beiträge zur vergleichenden Morphologie des Skeletsystems der Wirbelthiere. II Die Wirbelsäule und ihre Anhänge. Archiv. f. mikr. Anatomie, Bd. 15, 1878.

GreIL, A. Entwicklungsgeschichte des Kopfes und des Blutgefässystems von Ceratodus forsteri. SEMONS Forschungsreisen etc. Bd. I. Ceratodus, 1913.

Haswell, W. A. Studies on the Elasmobranch Skeleton. Proc. of the Linnean Soc. of New South Wales, Vol. 9, 1885. Hoffmann, C. K. Beiträge zur Entwickelungsgeschichte der Selachii. Morphologisches Jahrbuch, Bd. $25,1897$.

Koltzoff, N. K. Entwicklungsgeschichte des Kopfes von Petromyzon Planeri. Bulletin de Moscou, 1902.

KRAWETZ, L. Entwicklung des Knorpelschädels von Ceratodus. Bulletin de la Soc. Impériale des Naturalistes de Moscou. Année 1910, N. 1-3, 1911.

NeAL, H. V. The Development of the Hypoglossus Musculature in Petromyzon and Squalus. Anatom. Anzeiger, $\mathrm{N}^{\circ} .13,1897$.

NoordenBos, W. Ueber die Entwicklung des Chondrocraniums der Säugetiere, Petrus Camper, 3 de deel, 1905.

PeEters, J. L. E. Over de Ontwikkeling van het Chondrocranium en de kraakbeenige Wervelkolom van eenige Urodela en Anura. Diss. 1910.

Pehron, F. Some Points in the cranial Development of teleostomian Fishes. Acta zoologica, Bd. 3, 1922.

Regan, C. Tate. A Classification of the Selachian Fishes. Proc. of the Zool. Soc. of London, 1900.

- Descriptions of new or little known Fishes from the Coast of Natal. Annals of the Natal Government Museum, Vol. I, 1908.

SCAMmon, R. E. Normal Plates of the Development of Squalus acanthias. 12. Heft von KeIBELS Normentafeln zur Entwicklungsgeschichte der Wirbeltiere, 1911.

Schauinsland, H. Die Entwickelung der Wirbelsäule nebst Rippen und Brustbein. O. HerTwigs Handbuch der vergl. und experimentellen Entwickelungsgeschichte der Wirbelthiere, Bd. 3, Teil 2, 1905.

SCHREINER, K. E. Einige Ergebnisse über den Bau und die Entwickelung der Occipitalregion von Amia und Lepidosteus. Zeitschr. f. wiss. Zoologie, Bd. 72, 1902.

SEWERTZOFF, A. N. Die Entwickelung des Selachierschädels. Ein Beitrag nur Theorie der korrelativen Entwickelung. Festschrift für C. vON KUPFFER 1899.

- D Die Entwickelung der Occipitalregion der niederen Vertebraten etc. Bulletin de la Soc. Impér. des Naturalistes de Moscou, 1895, N. 2.

SMITH, Hugh M. Description of a new Notidanoid Shark from the Philippine Islands representing a new Family. Proc. of the United States National Museum, Vol. 41, 1912.

SonIEs, F. Ueber die Entwickelung des Chondrocraniums und der knorpeligen Wirbelsäule bei den Vögeln. Petrus Camper, 4 de deel, 1907.

VeIT, O. Beiträge zur Kenntnis des Kopfes der Wirbeltiere. I Die Entwickelung des Primordialcraniums von Lepidosteus osseus. Anatom. Hefte., Bd. 44, 1911.

White, P. J. The Skull and visceral Skeleton of the Greenland Shark, Laemargus microcephalus. Transactions of the Roy. Soc. of Edinburgh, Vol. 37, 1892.

WijHe, J. W. VAN. A new method for demonstrat!ng cartilaginous microskeletons. Proceedings der Kon. Akad. van Wetenschappen, Amsterdam, 1902.

- - Ueber die Entwicklung der Kopfskeletts bei Selachiern. Comptes rendus du 6 me Congrès international de Zoologie. Session de Berne, 1904.

- - Ueber die Mesodermsegmente und die Entwickelung der Nerven des Selachierkopfes. Verhandelingen der Kon. Acad. Amsterdam 1882. Neudruck 1915. 


\section{NACHSCHRIFT.}

Wenige Tage nach dem Absenden der dritten Druckprobe mit dem imprimatur erhielt ich die Septembernummer des Quarterly Journal of micr. Sc. (Vol. 66, Part 3, 1922) mit der Arbeit von RYLANDS DE BEER "The Segmentation of the Head in Squalus acanthias."

Auch DE BEER konnte die von HOFFMANN gefundene Zahl von 10 Kopfsomiten bei Acanthias bestätigen. Zwar erkannte er nur 9 Somite als solche an, da er nach dem Vorgange von GoodRICH in dem Intervalle zwischen dem Myotom des Abducens und dem ersten hinter dem Vagus aufsteigenden Muskelsegment nur 2 statt 3 abortive Somite annimt. Dies geschah aus theoretischen Gründen, auf welche ich hier nicht eingehen kann.

Dass aber tatsächlich in dem erwähnten Intervalle drei Somite angelegt werden, finde ich - wie bei Catulus - auch bei Acanthias.

Mir scheint, dass DE BEER von meiner Arbeit (1882) nicht viel verstanden hat. Auf Seite 11 derselben glaube ich bewiesen $\mathrm{zu}$ haben, dass BALFOUR sich irrte, als er die von ihm entdeckten Höhlen in den Visceralbogen für homolog hielt mit denjenigen in den Rumpfsomiten. Ich fand nämlich, dass sie nicht zu den Somiten, sondern zu den Seitenplatten gehören, da sie ventral mit der Perikardialhöhle zusammenhängen, was BALFOUR nicht bekannt war.

Auch hob ich hervor, dass die metotischen Somite niemals mit dén Höhlen in den Visceralbogen in Verbindung stehen.

Doch lässt DE BEER in seiner Textfig. 11a, welche ein Schema meiner Auffassung wiedergeben soll, die Somite 5, 6, 7, 8 ruhig je in einen Visceralbogen hineintreten und dort blind enden.

Welche Gründe er hat mit BALfour die Höhlen in den Visceralbogen für Somite zu halten, sagt er nicht.

Die Verhältnisse der Cölomkanäle in den Kiemenbogen von Amphioxus beweisen aber, dass eine solche Auffassung nicht richtig sein kann. Diese Kanäle münden bekanntlich an beiden Enden (dorsal und ventral) in das Cölom aus. Sie sind Teile desselben, welche durch die Kiemenspalten nur unvollkommen getrennt werden.

Bei Selachierembryonen sind die Höhlen in den Visceralbogen dorsal nicht in Kommunikation mit dem Rumpfcölom. Ventral sind dieselbèn aber eine zeitlang in die Perikardialhöhle geöffnet. Bei $12 \mathrm{~mm}$ langen Embryonen von Scyilium canicula (mit 89 Myotomen hinter dem Vagus) finde ich die Höhlen der hintersten Visceralbogen noch in die Perikardialhöhle offen.

Ich halte die Homologie der Visceralbogenhöhlen von Selachierembryonen mit den Cölomkanälen in den vorderen Kiemenbogen von Amphioxus für festgestellt. Aus den Wänden beider Gebilde entwickeln sich bei diesen Embryonen und bei Amphioxuslarven Muskelfasern, die mit der Somitenmuskulatur nichts zu schaffen haben.

G r o n ing e n, Oktober 1922. 


\title{
TAFELERKLÄRUNG
}

\author{
TAFEL XI
}

Sämtliche Figuren beziehen sich auf Embryonen von Acanthias vulgaris. Auf der Nebentafel ist der Knorpel durch einen grauen Ton angegeben. Er wurden drei Modelle des Chondrocraniums mit der Chorda und dem vorderen Teile der Wirbelsäule bis hinter dem Schultergürtel, dessen Knorpel gleichfalls in situ zur Darstellung kamen, bei 33 maliger Vergrösserung hergestellt. Jedes Modell wurde in Seitenansicht und Dorsalansicht photographiert. Die Photogramme haben ungefähr die halbe Grösse der Modelle.

Die Deutlichkeit der Photogramme ist bei der Reproduktion - auch bei den Textfiguren - grossenteils verloren gegangen. Die Nebentafel konnte wegen der Autotypie nicht korrigiert werden.

Fig: 1 $a$, Seitenansicht und Fig. 1b, Dorsalansicht nach einem Embryo von $23 \mathrm{~mm}$ Länge.

Fig. 2a, Seitenansicht, ziemlich schräg genommen, nach einem Embryo von $28 \mathrm{~mm}$ Länge. Der Deutlichkeit wegen

wurden vor dem Photographieren an der linken Körperseite der Kiefer- und Zungenbeinbogen, sowie die Trabecula und der Polknorpel entfernt. Diese Knorpel sind also nur von der rechten Körperseite dargestellt. Das Basihyale blieb in situ.

Fig. 2b, Dorsalansicht des ganzen Modelles (Vorderansicht sieh Textfig. 1)

Fig. 3a, Seitenansicht, etwas schräg genommen, nach einem Embryo von 391/2 mm Länge. Vor dem Photographieren wurden die linke Hälfte des Kiemenkorbes und der Skleralknorpel an beiden Körperseiten entfernt. Die Knorpel der Kiemenbogen sind also nur von der rechten Körperseite dargestellt. Das Cardiobranchiale blieb in situ.

Der weisse Flecken unter $o b$ ist kein Hypoglossusforamen, sondern eine kleine Stelle, an welcher der erste Wirbelkörper noch nicht mit dem Schädel verschmolzen ist und die Chorda noch frei zu Tage liegt.

Fig: 3b, Dorsalansicht des ganzen Modelles mit Ausnahme des Skleralknorpels. (Vorderansicht sieh Textfig. 4).

\section{BUCHSTABENERKLÄRUNG}

$b d_{4}, b d_{11}$ Das 4., 11. dorsale Basale. $b$ hy Basihyale.

$b s d$ Dorsaler Basalstreifen. ( $b 3 d$ auf Fig. 2a).

bs $v$ Ventraler Basalstreifen.

$b v_{i 1}$ Das 11. ventrale Basale.

$c a b$ Cardiobranchiale.

c al Cartilago anterolateralis der Ohrkapsel.

$c b_{1}, c b_{5}$ Erstes, fünftes Ceratobranchiale.

$c d$ Chorda dorsalis.

$c h$ Chordahaken.

co Coracoid.

$c p$ Cartilago posterior der Ohrkapsel. Die Führungslinie (zwischen Fig. $2 a$ und $2 b$ ein wenig nach rechts zu verlä̀nger).

$e b_{1}, e b_{5}$ Erstes, fünftes Epibranchiale.

$f$. car Foramen caroticum.

$f d$ Dorsalwärts gerichteter Fortsatz des Parachordale hinter der Eintrittsstelle des N. acusticus in das Gebiet der Ohrkapsel. (Anlage der medialen Kapselwand).

$f t$ Foramen des $\mathrm{N}$. trochlearis.

$f t^{1}$ Dasselbe Foramen der andern Körperseite.

hm Hyomandibulare.

hy Ceratohyale.

$h y^{1}$ Dasselbe der andern Körperseite.

$i_{1}, i_{4}, i_{5}$ Erstes, viertes, fünftes Intercalare.

$i$ a $o$ Incisura antotica.

i $m o$ Incisura metotica.

i $m o^{1}$ Dieselbe Incisur der andern Körperseite.

io Incisur für den N. oculomotorius.

$i o^{1}$ Dieselbe Incisur der andern Körperseite.

is $o$ Incisura suboccipitalis für die ventrale Wurzel des 1. Spinalnerven (Suboccipitalnerven). itr $s$ Intertrabecularschlitz.

la $c$ Lacune in der vorderen, oberen Ecke des Orbitalrahmens.

l b Lamina basiotica des Parachordale.

Io $n$ Lamina orbitonasalis.

$m$ Mandibula.

$m^{1}$ Dieselbe der andern Körperseite.

$m_{1}, m_{2}$ Proximale, distale Mandibularknorpelanlage. $m r s$ Medianer Rostralstab.

$o b$ Occipitalbogen.

$o k$ Ohrkapsel.

p a Parachordale.

$p b_{1}, p b_{4}$ Erstes, viertes Pharyngobranchiale. pf Polfenster. po Polknorpel.

$p o^{*}$ Derselbe nach der Verschmelzung mit der Trabekel und dem Parachordale.

$p p t$ Processus palato-trabecularis.

$p q$.Palatoquadratum.

$p q^{1}$ Dasselbe der andern Körperseite.

ps Pleurosphenoid.

sc Scapula.

$s g$ Schultergürtel.

tr Trabecula.

$\operatorname{tr} p$ Trabekelplatte, von Anfang an unpaare Fortsetzung der paarigen Trabekeln.

$y$ Foramen der vorletzten Hypoglossuswurzel. Die Führungslinie ist etwas zu kurz und das Foramen $\mathrm{zu}$ weit ausgefallen.

$z$ Foramen der letzten Hypoglossuswurzel. 


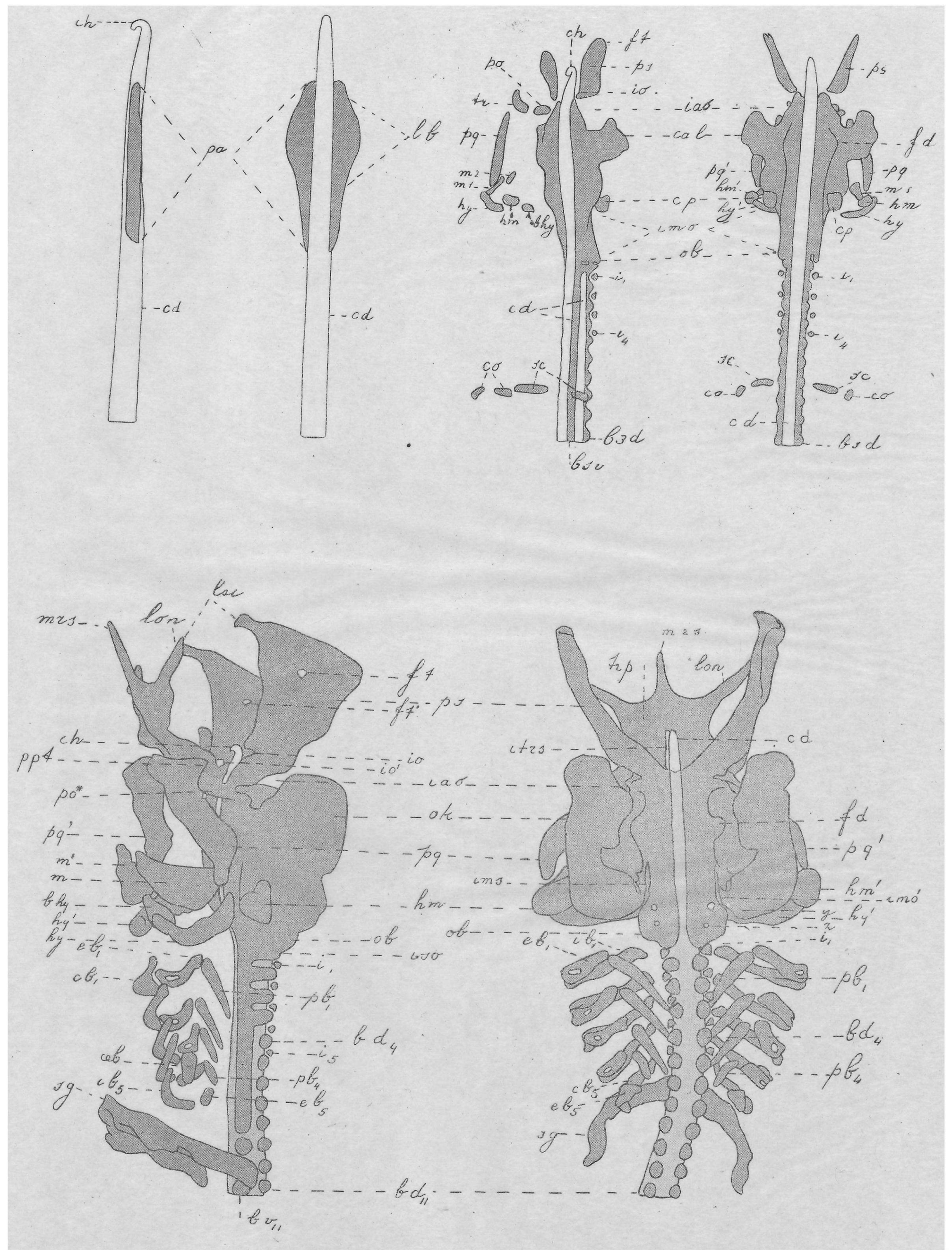




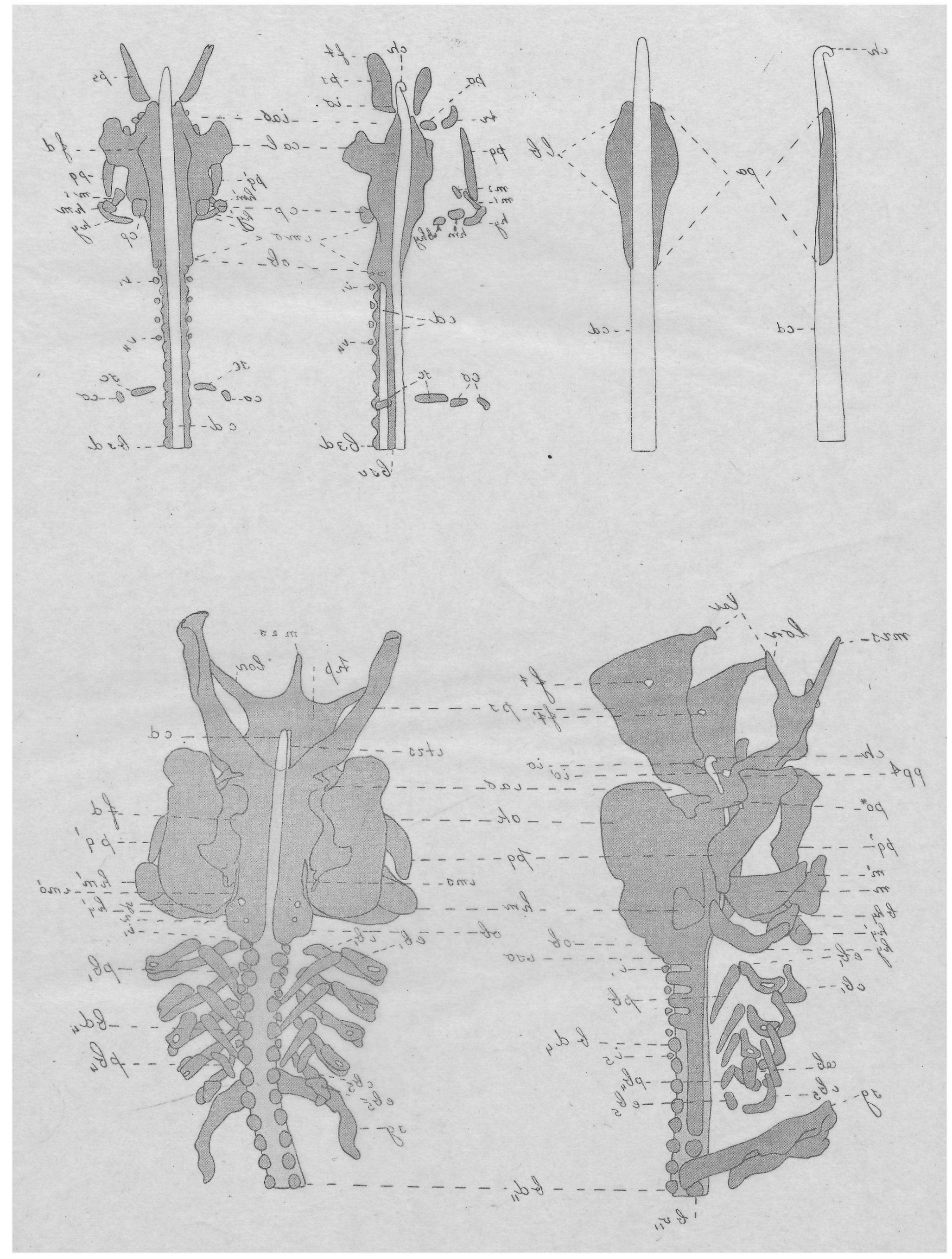


$1 a$

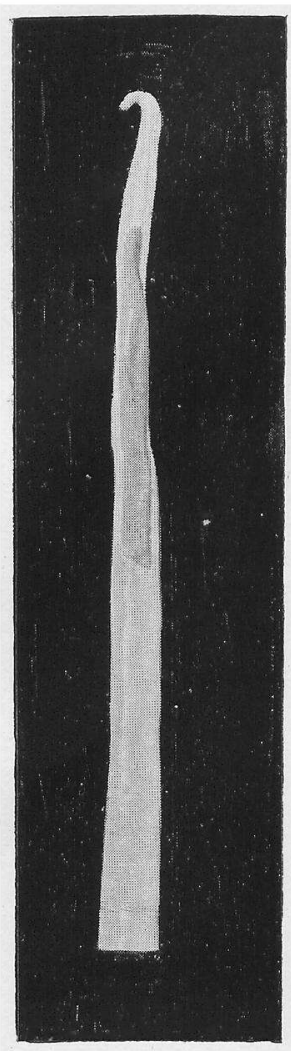

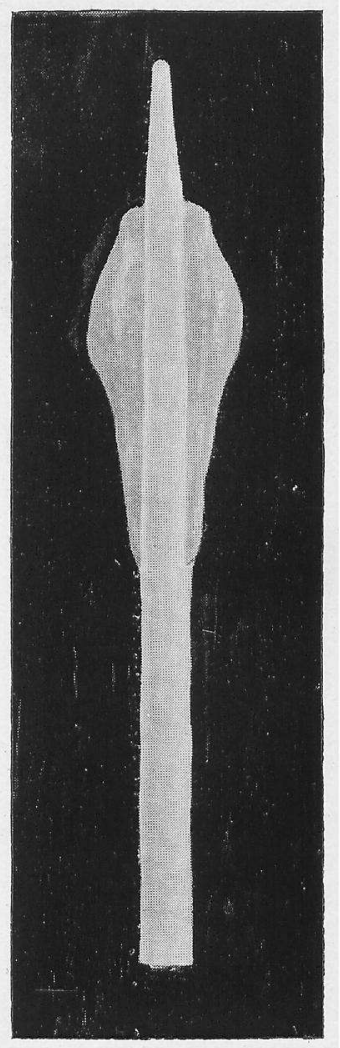

$3 a$

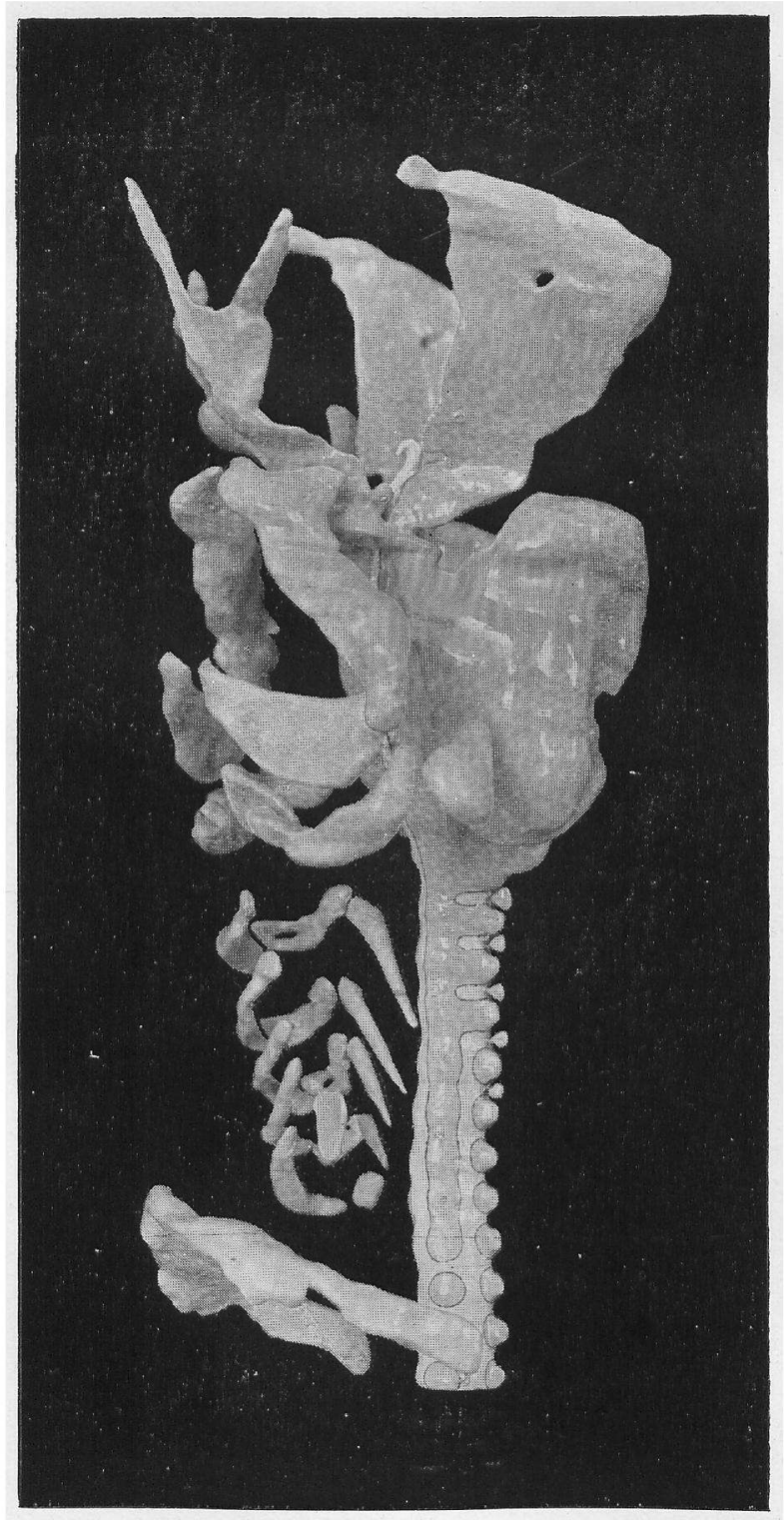

$2 a$
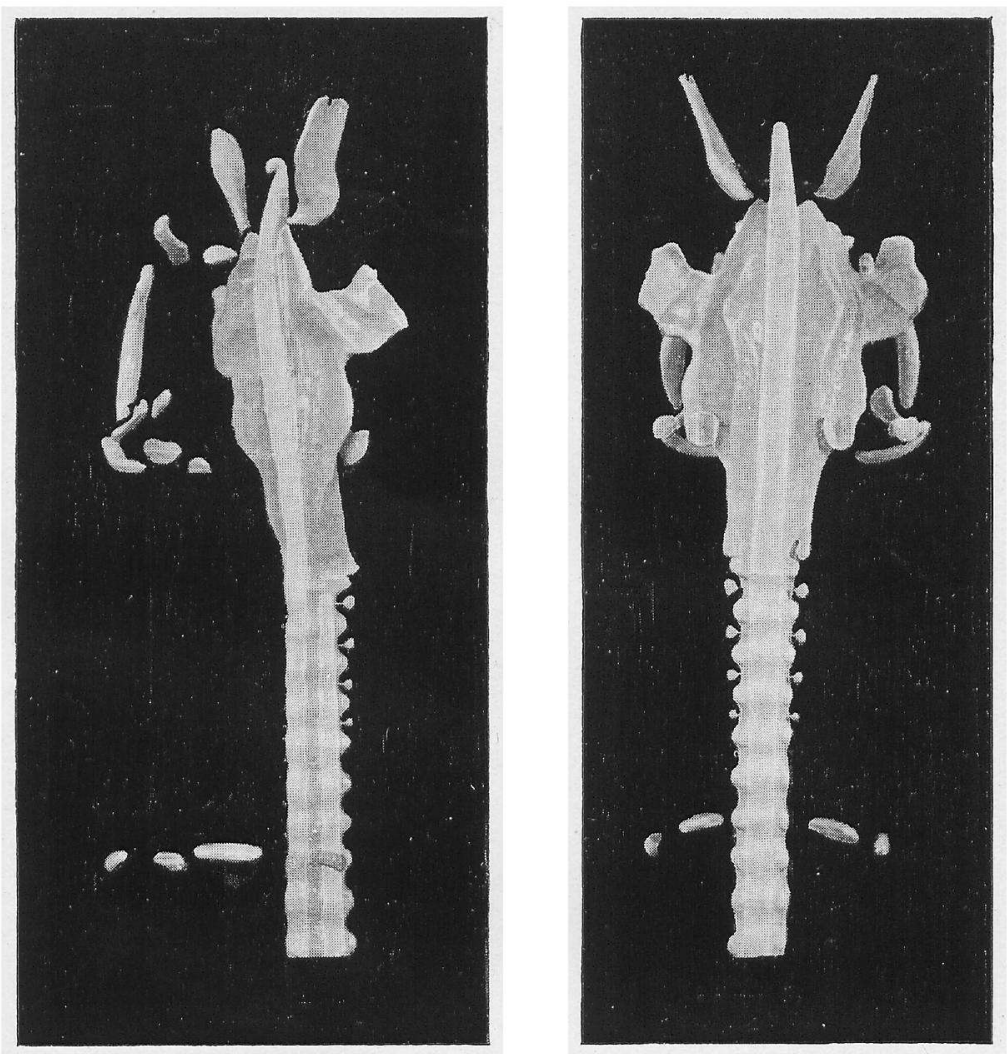

$3 b$

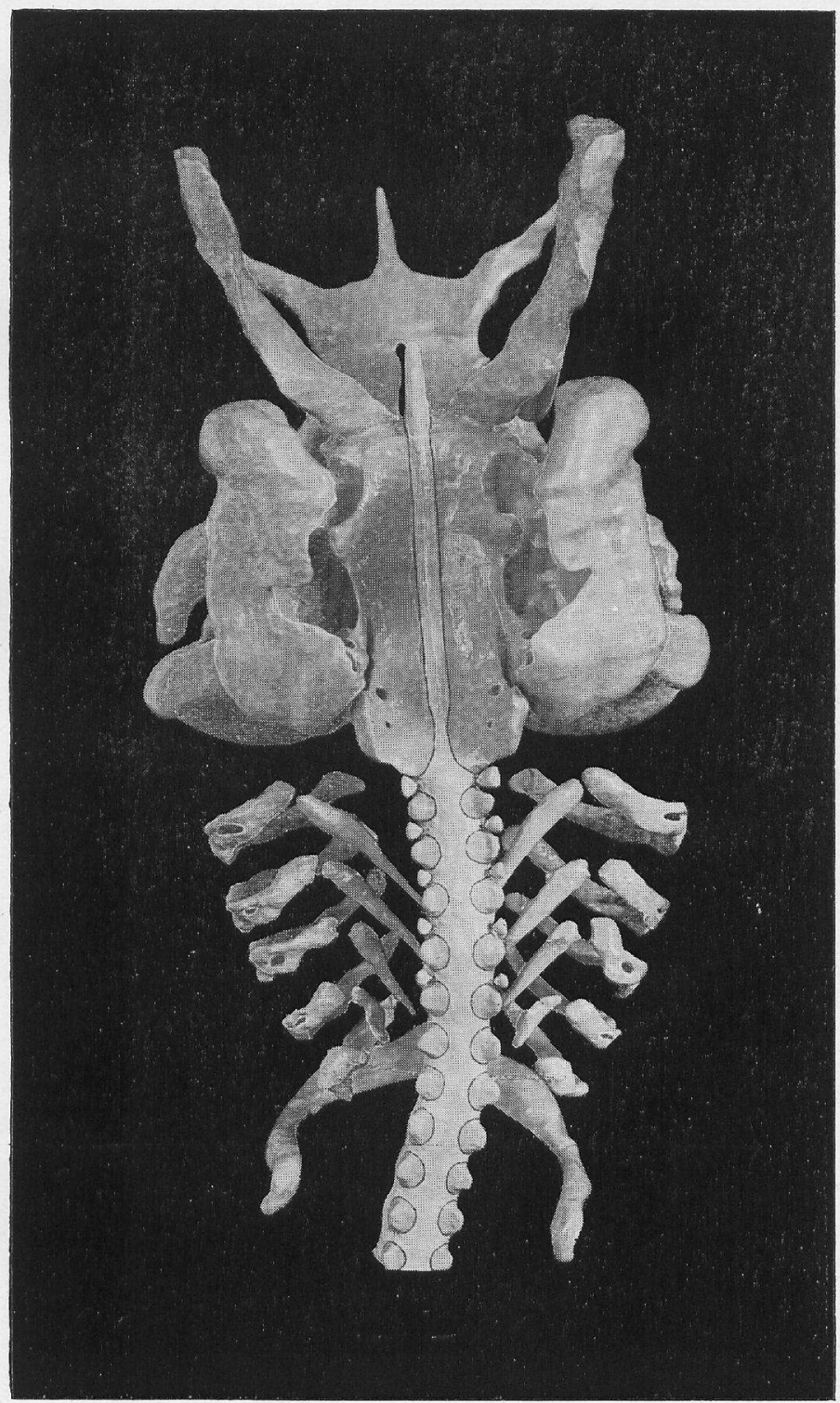

